\title{
Referencias históricas y aportes jurídicos en la consideración como persona humana del indio peruano durante la Conquista ${ }^{1}$ Rafael Santa María D'Angelo²
}

\begin{tabular}{ll} 
INFORMACIÓN DEL ARTÍCULO & RESUMEN \\
\hline $\begin{array}{l}\text { Historia del artículo: } \\
\text { Recibido el } 10 \text { de junio de } 2012\end{array}$ & La historia del derecho peruano brinda en su etapa inicial un aporte de alcance \\
Aceptado el 5 de julio de 2012 & universal, a partir de los cuestionamientos sobre la humanidad de los nativos andinos. \\
& La reflexión de Francisco De Vitoria y la Escuela de Salamanca representa una gran \\
\hline Palabras clave: & riqueza en el reconocimiento de la naturaleza humana, del carácter social y el derecho \\
Indio peruano & natural a la comunicación expresada en sus justos títulos. Estos presupuestos, además \\
persona humana & de conservar un valor histórico, mantienen una actual vigencia jurídica en la \\
derecho indiano & consideración de todo ser humano como sujeto de derecho.
\end{tabular}

Historical references and legal contributions in the consideration as a human person of the Peruvian Indian during the Conquest

\section{Introducción}

Responder a la interrogante si los indios peruanos eran considerados personas humanas durante la Conquista no resulta fácil, pues para ello se requiere antes situarnos en una serie de -escenarios históricos, donde de una parte encontramos el declive del Imperio Incaico con toda la consecuencia que esto significo al interno del Tahuantinsuyo; y de otra, la llegada de los españoles al territorio andino, con el efecto que esto represento tanto para España como para el mundo occidental.

Entender este encuentro cultural nos da la base para luego, con mayores elementos, responder a la interrogante planteada 3 .

Por lo extenso que representa esta respuesta, no nos limitaremos a detalles históricos, sino más bien trataremos de responder destacando algunos hechos y aportes dados durante este tiempo con especial énfasis sobre el estatuto personal de los nativos peruanos.

\section{SITUACIÓN DEL IMPERIO INCAICO ANTES DE LA LLEGADA DE LOS ESPAÑOLES}

No cabe duda sobre la existencia de todo un sistema cultural, económico, político, social y normativo en el Incanato. Sistema que fue madurando en modo especial a finales del siglo XV y comienzos del XVI ${ }^{4}$.

Una de las principales causas de la caída del Tahuantinsuyo, fue la división existente, tanto al interno de la nobleza inca, como en el resto del Imperio Incaico.

Al interno de la nobleza inca, se evidenció la guerra fraticida entre los sucesores del inca Huayna Cápac, luego de su muerte en 1525. Sus hijos: Huáscar y Atahualpa se enfrentaron por suceder al Inca, venciendo Atahualpa, quien

\footnotetext{
${ }^{1}$ Este artículo con algunas modificaciones se extrae del segundo capítulo de la obra del autor: El principio de la dignidad de la persona humana y la aparición de -nuevos derechos en el ordenamiento jurídico peruano contemporáneo, Pontificia Universitas Lateranense, Roma 2007. Pp. 131- 168

2 Doctor en Derecho por la Pontificia Universidad Lateranense, Coordinador del Área de Historia y Filosofía del Derecho de la Facultad de Derecho de la Universidad Católica Santo Toribio de Mogrovejo, Chiclayo (Perú)

${ }^{3}$ En este sentido, trataremos modestamente de aproximarnos a estos - escenarios, destacando la síntesis histórica que representa para el Perú la formación de la cultura mestiza.

${ }^{4}$ ¿Qué le debemos al mundo andino? ¿Por qué decimos que sin lo andino no existe el Perú? En primer término debemos recordar que el mundo andino creó una civilización original, una de las pocas civilizaciones en la historia del mundo que se hizo sola, sin modelo, sin ejemplo que imitar. Esta es una idea central que debe llevarnos de la mano a ver con respeto y con gratitud un mundo que se hizo solo; que dominó una geografía difícil; que inició la pesca y la agricultura en nuestro medio; que domesticó a los animales; que en el tejido, en las construcciones, en el dominio de técnicas aun no conocidas en su integridad, creó una sociedad con medios de comunicación, de producción y organización social y política; le debemos, en fin, a la cultura andina la continuidad de sangre que se puede advertir sin esfuerzo en todo peruano viejo...// DE LA PUENTE CANDAMO JOSÉ AGUSTíN, Reflexiones sobre la identidad nacional, Revista Persona y Cultura No 4, Universidad Católica San Pablo. Arequipa- Perú. Pp. 30
} 
ordenó asesinar a su hermano y matar a todos los miembros de la familia real que pudieran intentar destronarle.

En el Imperio Incaico, se evidenciaba una falta de integración al no tener entre los nativos conciencia de unidad. No existió en los indios del Incanato el concepto de una nación, pese a los ensayos del Inca de implantar una misma lengua en todo el Imperio.

Además, el sistema implantado por los incas resultaba para algunos curacas y grandes señores una pérdida de poder y riquezas, al pasar las tierras al Estado, con la gente local trabajando sus campos y el usufructo llenando los depósitos gubernamentales. Todo esto mostraba un descontento en buena parte de la población inca.

Por otro lado, el asombro de los indígenas ante la llegada de los españoles en 1532 fue grande. Los indios no conocían las armas portadas por los hispanos (los arcabuces, falconetes, espadas de acero y los caballos). - -... Hasta la misma extensión del Tahuantinsuyo favoreció a los invasores, haciéndolo más vulnerable y menos pronto a la resistencia ${ }^{5}$. Es importante señalar que, ante la llegada de los españoles al territorio inca, éstos fueron en gran parte ayudados por los señores indígenas. Se considera que más que un gran ejército hispano que apresó al Inca, fueron los propios andinos, quienes descontentos con la situación imperante creyeron encontrar una ocasión favorable para recobrar su libertad ${ }^{6}$.

\section{SITUACIÓN EN ESPAÑA ANTES DE LA CONQUISTA DEL PERÚ}

Para tener presente el -legajo que portaron los primeros españoles al llegar a tierras peruanas es necesario considerar algunos aspectos históricos tanto en España como en Europa durante el siglo XVI.

Un primer aspecto que importa destacar era la unidad cultural vivida en aquel tiempo en el viejo continente, expresado de forma institucional por la Iglesia Católica ${ }^{7}$. Unidad no ajena a conflictos a nivel político, religioso y social. En España, esta integración se fue gestando a partir del reinado de Isabel y Fernando II, Ilamados también los Reyes Católicos ${ }^{8}$.

\footnotetext{
${ }^{5}$ VARGAS UGARTE RUBÉN, Historia de la Iglesia en el Perú (1511- 1568) Tomo I. Imprenta Santa María. Lima 1953. Pp. 13.

${ }^{6}$ Cfr. BASADRE JORGE, Historia del Derecho Peruano. Ediciones Graficas S.A. Segunda Edición. Lima 1984, Pp. 123- 126.

${ }^{7}$ Al respecto señala el profesor italiano Francesco Calasso: -... Come si vede, un'idea sta al centro di questa concezione: il principio d'unità, o, come i filosofi dissero, della reductio ad unum. In che cosa consisteva questo principio, che fu una delle espressioni più tipiche del pensiero medievale? Osserviamo anzi tutto che esso non nacque nel mondo del diritto, ma venne mutuato dalla speculazione pura, sulla base del pensiero aristotelico, che tornava anch'esso in onore per avventura in quel secolo stesso della reviviscenza dei testi giustinianei genuini. Attorno all'opera del filosofo greco si era acceso un intenso travaglio di pensiero, che con lo strumento della esegesi cercava di risolvere il grande problema di adattare alla civiltà cristiana questo edificio colossale ereditato dal mondo classico pagano.... Ora, nel pensiero aristotelico, I'assioma della reductio ad unum rappresenta un principio d'ordine universale, che dal mondo della natura si riflette sul corpo sociale: I'universo tutto è governato da un ordine, che è Dio; e Dio è unità, nella quale la molteplicità si dissolve. La speculazione medievale si appropria il principio, e ne fa il pernio della sua filosofia politica...// CALASSO FRANCESCO, Medioevo del Diritto. I- Le fonti. Giuffrè Editore. Milano 1954. Pp. 371- 372
}

Dada la diversidad de hechos y situaciones históricas contemporáneas en esta época, interesa centrarnos especialmente en lo siguiente: el descubrimiento de América, las Bulas Pontificias de Alejandro VI, el derecho español previo a la conquista del Perú y finalmente los factores que impulsaron la conquista del Perú.

\section{a) El descubrimiento de América}

No es propósito detallar los viajes realizados por Cristóbal Colón, sino más bien destacar lo acontecido el 12 de Octubre de 1492, no sólo como un hecho que significó una sorpresa en ese entonces para España y para el mundo entero, sino más bien como el encuentro entre dos mundos con un profundo significado.

-... supuso un impresionante ampliación del horizonte geográfico y humano para los pueblos del occidente europeo, traducido en nuevos conocimientos de hechos físicos y naturales hasta entonces ignorados. Pero se limitaría mucho esta ampliación del horizonte si sólo nos refiriésemos a dichos hechos, ya sean geográficos, marítimos, botánicos o zoológicos; fue también el horizonte humano, moral, espiritual y filosófico el que se dilató, planteando problemas. Es así la esfera mental, espiritual y cultural la que también se amplía, configurando la entrada de un nuevo período de la historia humana. El perfil de la Edad Moderna es inconcebible sin ese conjunto de hechos y problemas que va a traer la presencia del continente descubierto... ${ }^{9}$

Este encuentro cultural se dio en un tiempo favorable para España. Finalizadas las guerras de la reconquista, los reyes de España vieron en los descubrimientos una magnífica oportunidad para reforzar la unidad e integración de los reinos, así como para favorecer el impulso expansivo a nivel político y económico; sobre todo la oportunidad de portar el conocimiento de la fe católica a nuevas realidades, situación esta última que se complementaba con el celo misionero de Cristóbal Colón ${ }^{10}$. Es así que el acuerdo entre éstos quedo formalizado con la Capitulación de Santa Fe en abril de 1492. Naturalmente, con el encuentro del "nuevo mundo", los horizontes se ampliaron y el mundo físico y material se

\footnotetext{
${ }^{8}$ Con el matrimonio de Isabel de Castilla con Fernando II de Aragón en 1469, se logró el inicio de una poderosa monarquía, que posteriormente sus herederos la llevarán a una basta extensión territorial en tres continentes. ${ }^{9}$ ABELLÁN JOSÉ LUIS, Los eclesiásticos y las ciencias profanas. BORGES PEDRO (Dir.), Historia de la Iglesia en Hispanoamérica y Filipinas (Siglos XV$X I X)$ Volumen I: Aspectos Generales. Biblioteca de Autores Cristianos. Madrid 1992. Pp.731

${ }^{10}$ Sobre la personalidad de Colón señala Arranz: -...Uno de los signos más destacados que caracterizan la personalidad de Cristóbal Colón -aunque a algunos les parezca extraño- es el de ser y sentirse, religiosa y culturalmente hablando, un hombre medieval, una persona con la imaginación, credulidad e ignorancia características del Medioevo y, como tal, proclive a dar a sus actos, ideas y proyectos, sobre todo si eran tan inesperados como trascendentales, un sentido religioso profundo. $Y$ a medida que avanza el tiempo y se confirma la importancia de lo descubierto, lejos de mitigarse ese sentimiento, se arraigará en él un mesianismo profético, una profunda convicción de ser el siervo elegido por la Providencia, el predestinado, el portador de Cristo o apóstol de los nuevos pueblos a través de cuya acción descubridora ha de extenderse el Evangelio.// ARRANZ MÁRQUEZ LUIS, La Iglesia y el descubrimiento de América. Borges Pedro (Dir.), Historia de la Iglesia en Hispanoamérica y Filipinas (Siglos XV-XIX) Volumen I: Aspectos Generales. Biblioteca de Autores Cristianos. Madrid 1992., pp. 22
} 
convirtió en un objeto de curiosidad intelectual. Se abrió, además, un nuevo mercado derivando de ello mucha riqueza para la Corona Española.

Inicialmente se pensaba haber alcanzado "la India", o una prolongación natural y cercana de la India y demás tierras orientales de Asia, por esto quedaron bautizadas las tierras con el nombre de las Indias ${ }^{11}$. Años más tarde, con la certeza de un nuevo continente, estas tierras fueron llamadas América ${ }^{12}$. Luego comenzarán a referirse a parte del nuevo continente como Hispanoamérica ${ }^{13}$.

Con el descubrimiento de América, y las posteriores colonias, España fue convirtiéndose en una potencia mundial, creando el -Imperio Español|| con una extensión territorial, a finales del siglo XVI, en Europa, América, Asia y África.

\section{b) Las Bulas Pontificias de Alejandro VI}

El año siguiente al descubrimiento de América, España comienza negociaciones sobre la soberanía de las tierras descubiertas ante Portugal y, en las cuales interviene el Romano Pontífice.

En 1493 el Papa Alejandro VI promulga cuatro Bulas Papales, conocidas como las Bulas Alejandrinas ${ }^{14}$. La promulgación de estos documentos pontificios expedidos a favor de los Reyes Católicos estuvo motivada por el interés de éstos en mantener exclusividad sobre el dominio de los territorios

11 Tanto así que como veremos posteriormente, se extendió esta denominación al derecho: como se conoció así al derecho indiano.

${ }^{12} \mathrm{El}$ nombre del nuevo continente fue un homenaje al navegador italiano Américo Vespucio, quién durante los años 1499 a 1502 logró realizar diversos viajes por estos territorios.

${ }^{13}$ - Bajo el término de Hispanoamérica se engloban todos los territorios en los que desarrolló su actividad España desde 1492 hasta 1824, fecha esta última que se adopta, a pesar de su inexactitud, como el punto final del proceso de independencia o emancipación de las actuales naciones hispanoamericanas. Se trata, por lo mismo, de un concepto geográfico distinto de lo que inadecuadamente se suele denominar América latina o Latinoamérica, pues excluye a Brasil pero incluye también a California, todo el sur de los Estados Unidos y el sureste de esta misma nación/l. BORGES PEDRO, Historia de la Iglesia en Hispanoamérica y Filipinas. BORGES PEDRO (Dir.), Historia de la Iglesia en Hispanoamérica y Filipinas (Siglos XV-XIX), Ob. Cit. Pp. 6

${ }^{14}$ Los documentos Pontificios fueron los siguientes: 1. La primera Inter caetera, del 03 de mayo de 1493, por la que el Papa concede a los Reyes Católicos todas las tierras e islas firmes, descubiertas ya o que se descubrieran en el futuro, siempre que no estuvieran sometidas a algún príncipe cristiano y bajo la condición de que enviaran a ellas evangelizadores. Es la denominada bula de donación; 2. La segunda Inter caetera, del 4 de mayo de 1493, denominada también bula de partición o de demarcación, pues recoge muchos pasajes de la anterior, a la que amplía y concreta. En esta se establece una raya o línea divisoria trazada de norte a sur por el meridiano que pasa a cien leguas de la islas Azores y Cabo Verde, para delimitar las zonas de expansión de Castilla y Portugal en el futuro. 3. Eximiae devotionis, del 03 de julio de 1493, reproducción en parte de las dos anteriores y que concede a los reyes de Castilla y León, para las tierras que descubrieran, los mismos privilegios otorgados anteriormente a Portugal para los territorios descubiertos en África. 4. Dudum siquidem, del 25 de septiembre de 1493, muy breve en comparación con las tres anteriores, por la que se amplía la donación «a todas y cada una de las islas y tierras firmes halladas o por hallar, descubiertas o por descubrir, que estén, o fuesen, o apareciesen a los que navegan o marchan hacia el occidente y aun al mediodía, bien se hallen tanto en las regiones occidentales como en las orientales y existen en la India». Es la denominada bula de ampliación.

15 Para una comprensión del tema, es necesario referir, aunque muy sumariamente, el modelo de teoría política medieval, en cuanto concierne descubiertos, y por seguir descubriendo nuevos territorios. De esta manera, limitando las pretensiones de otros monarcas europeos que quisiesen participar en los frutos del descubrimiento, sobre todo por parte del rey portugués.

En Junio de 1494, se suscribió el Tratado de Tordesillas entre Portugal y la Corona de Castilla, por el que se definía la denominada línea de demarcación, que establecía los límites entre las zonas que pasarían a ser gobernadas por España y las que pertenecerían a Portugal.

Un significativo problema que surgió a causa de los mencionados documentos Pontificios, era en base al fundamento jurídico que sirvió al Papa Alejandro VI donar a los Reyes Católicos estos territorios ${ }^{15}$.

Es notable la evolución en la opinión de los juristas en este tiempo. Inicialmente la posición más común fue la monística hierocrática por la que el Papa había recibido de Cristo el dominio del mundo, y por ello el Papa Alejandro VI concedió las Indias a los Reyes Católicos, exigiéndoles a cambio que estas tierras sean evangelizadas.

Luego, el dualismo sostendrá que el Papa no tiene ningún dominio temporal sobre el mundo, ni puede hacer ninguna donación por justo título. Sin embargo puede hacer todo lo necesario para cumplir con el derecho y el deber que tiene de anunciar el Evangelio y proveer al bien espiritual de las almas encomendadas ${ }^{16}$.

a las relaciones entre el poder espiritual y el poder temporal. Existía un acuerdo que ambos poderes vienen de Dios, pero el desacuerdo empieza al determinarse a través de quién se transmitía este poder a los seres humanos. Es así que se distinguen dos posiciones: la monista y la dualista. Los monistas defendían que el poder se transmitía de Dios a los hombres mediante una sola persona, algunos consideraban que esta persona era el Papa (monismo hierocrático), otros el Emperador o los reyes (monismo laico). El dualismo, en cambio, sostiene que el poder viene de Dios a los hombres por dos vías independientes: el poder secular (a través del príncipe temporal), y el poder espiritual (a través de la jerarquía de la Iglesia). En el mismo dualismo había dos matices importantes: algunos pensaban que el poder espiritual se transmitía de Dios a la Iglesia solamente por medio del Papa, y otros también a través de los Obispos. Algo similar ocurría en la esfera temporal, donde se sostenía que el poder se transmitía sólo a través del emperador, mientras que otros creían que también se transmitía a los demás príncipes temporales, como los Reyes. Dentro de la posición del dualismo se ensayan luego algunos principios que sirven de base para la relación de lo espiritual con lo temporal, expresando así la distinción e independencia entre ambos (generalmente se admitía una cierta superioridad del poder espiritual sobre el temporal), no obstante la puesta en práctica de este principio constituyó una fuente inagotable de problemas y litigios entre ambos poderes. Una explicación histórica de estas teorías la encontramos en DALLA TORRE GIUSEPPE, La città sul monte. Contributo ad una teoria canonistica sulle relazioni fra Chiesa e Comunità politica. Editrice AVE. Seconda Edizione. Roma 2002. Pp. 27- 36.

${ }^{16}$ Según el profesor español Antonio García y García: -...Las teorías para explicar el fundamento jurídico de la donación pontificia se reducen a cinco: monística hierocrática, arbitral, feudal, el título de la inventio o res nullius (hallazgo o cosa sin dueño) y la dualista. Según la teoría monística hierocrática, Dios habría otorgado el dominio del mundo a Cristo, Cristo al Papa y éste habría donado a los reyes de Castilla una parte tan importante del orbe como son las Indias. La teoría arbitral supone que el Papa actuaba como árbitro entre los reyes castellanos y el portugués, y estos documentos vienen a resolver la cuestión de los límites entre los dominios de una y otra monarquía en su expansión hacia Occidente. En realidad, el lenguaje de la bula parece irreconciliable con esta teoría del arbitraje, ya que en ella se afirma: concedimus et donamus (concedemos y donamos) por la autoridad del Papa y no en virtud de los poderes conferidos por las partes a un árbitro.... la donación alejandrina no fue un arbitraje técnicamente hablando, pero el Papa sí tuvo que pronunciarse por una de las dos opciones 
Claramente que cuando se expidieron los documentos Pontificios no existían noticias veraces sobre la total extensión de los nuevos territorios. Además la Iglesia por sí misma en ese tiempo, no tenía los medios necesarios para llevar a cabo la evangelización a esta nueva población; punto que se complementa con otro aspecto: que en esta cuestión que el requerimiento de los documentos pontificios por parte de los Reyes Católicos respondía también al deseo de preservar este Nuevo Mundo contra otros monarcas cristianos. Todo esto, explica la confluencia de la teoría dualística propia de este tiempo.

\section{c) El derecho español previo a la Conquista del Perú}

La historia del derecho español previa al siglo XVI es inmensamente rica por la mezcla de tradiciones jurídicas.

Un primer elemento que resulta de base, es la fuerte romanización de la Península Ibérica. Después de la caída del Imperio Romano de Occidente en el año 476 d.C., los visigodos tuvieron a nivel jurídico como referente inspirador al derecho romano, muestra de ello son la lex visigotorum y la lex romana visigotorum ${ }^{17}$.

Posteriormente con la invasión de los árabes en el siglo VIII y la reconquista que duró hasta el siglo $\mathrm{XV}$, se produce una división religiosa, política, social y jurídica, no obstante en esta fractura religiosa- política vemos como tradiciones romano- visigodos llegan a prevalecer.

Una institución que destaca en el derecho propio hispano son los denominados Fueros. Eran un conjunto de textos y

posibles al solicitarle los reyes castellanos que se pronunciara por el dominio exclusivo de éstos sobre aquellos territorios. Otros autores, explican este problema diciendo que el Papa concede en feudo aquellas tierras a los reyes castellanos, por lo que el título de conquista y retención de las tierras del Nuevo Mundo se basaría en el hecho de que los reyes de Castilla poseían aquellos territorios como feudatarios de la Santa Sede. Como es obvio, esta teoría feudal presupone la aceptación de la teoría monística hierocrática, en virtud de la cual podría el Papa dar en feudo las tierras del Nuevo Mundo a los reyes de Castilla. Es, pues, una especificación ulterior de la teoría monística hierocrática. Otros, en fin, explican la donación de las Indias en virtud de una doctrina del derecho romano, que constituye todavía hoy un título originario del dominio de las cosas, a saber, el hallazgo de las mismas sin que pertenezcan a ningún dueño. Se conoce como la teoría de la inventio o de la res nullíus (hallazgo o cosa sin dueño). Según esto, más que de una donación, se trataría de un reconocimiento por parte de la Santa Sede de que los reyes castellanos poseían legítimamente las Indias en virtud del título de haberlas descubierto $v$ de que no tenían dueño o, lo que es lo mismo, no había allí reinos constituidos. Ciertamente que al filo de 1493 tal vez se podía pensar de buena fe que ésta era la situación. Posteriormente, con el descubrimiento de reinos como el de los aztecas de México y el de los incas del Perú, ya no se podía afirmar tal cosa. Pero, en todo caso, esta teoría parece contraria al texto de las bulas alejandrinas, ya que allíno se habla de ningún reconocimiento, sino de donación, puesto que se usan las palabras concedemos y donamos Desde la teoría dualista, según la cual el Papa podría hacer todo lo necesario para cumplir la misión espiritual de la Iglesia en el mundo en su doble vertiente, la salvación de los cristianos y la evangelización de los que todavía eran infieles. .../ GARCÍA Y GARCÍA ANTONIO, La donación pontificia de las Indias. Borges Pedro (Dir.), Historia de la Iglesia en Hispanoamérica y Filipinas (Siglos XV-XIX). Ob. Cit. Pp. 33-46

17 Señala Cortese: “...nell'ultimo anno del regno di Tolosa, e poi per un secolo e mezzo in quello iberico.... visigoti ebbero due leggi... Si trattava di due leggi personali: interveniva cioè a ripartirne regolatamente l'uso il principio della personalità del diritto, per il quale soggetti di un medesimo ordinamento politico potevano usare sistemi normativi diversi a seconda dell'etnia di appartenenza. Sicché la Lex Romana Wisigothorum sarebbe costumbres que recogen privilegios y tradiciones territoriales reconocidas por la autoridad y utilizadas en el Tribunal ${ }^{18}$.

Relevante además en el derecho hispano es la recepción del Derecho Común, que expresaba un carácter fundamental de este periodo medieval: una reductio ad unum de carácter religioso y filosófico, que indudablemente incidió en lo político y en lo jurídico.

Si bien en el derecho romano la expresión ius commune era considerada como aquel derecho que vale para todos, y la expresión ius proprium era aquel derecho que vale sólo para algunos $^{19}$. En la Alta Edad Media, propiamente en Bolonia: en la Escuela deBolonia ${ }^{20}$, el derecho común cambia y se vuelve un concepto técnico, fijo, típico y definido, como unidad. El contenido de este derecho era la legislación justinianea. De esta manera, todo aquello que no era derecho común (derecho romano justinianeo), resultaba considerado como derecho propio.

Tengamos presente que en el medioevo, los dos ordenamientos de alcance universal eran el Imperio y la Iglesia Católica, por lo que tenemos un discurso de derecho común tanto desde el punto de vista civil como desde el punto de vista eclesial. De esta manera, como sistema y como ciencia, el derecho común comprenderá al derecho civil y al derecho canónico: el Utrumque lus, que encontrará en la Escuela un tentativo de unidad sólo a partir de la promulgación del Liber Extra del Papa Gregorio IX en el año $1234^{21}$. El método utilizado de los estudiosos en Bolonia será el método de la Glosa.

stata adoperata solo dai Romani, la Lex Visigothorum solo dai Goti... Ma nella legge visigota non erano raccolte tradizioni germaniche: essa conteneva al contrario un insieme di regole tratte dalla prassi volgare romana...." CORTESE ENNIO, Le grande linee della Storia Giurudica Medievale. II Cigno G.G. Edizioni. IV. Roma 2004. Pp. 45- 46. Una explicación de la importancia de la Lex Romana Wisigothorum la encontramos en ARANGIO- RUIZ VICENTE, Historia del Derecho Romano. Biblioteca Jurídica de Autores Españoles y Extranjeros. Editorial Reus S.A. Madrid 1999. Pp. 451.

${ }^{18}$ Sobre los Fueros, refiere Germán Doig: - ... Estos Fueros recogen, de una manera más o menos clara, los principios cristianos sobre la persona humana, y constituyen uno de los primeros hitos en el derecho positivo en el camino hacia la configuración de un elenco de los derechos fundamentales del hombre...// DOIG GERMÁN, Derechos humanos y la Enseñanza Social de la Iglesia. Asociación Vida y Espiritualidad. Lima 1991. Pp. 84.

${ }^{19}$ Citando a Gayo en el Digesto (D.I.I.9), el profesor Calasso sostiene: “....-Omnes populi qui legibus et moribus reguntur partim suo proprio partim communi omnium hominum iure utunturll: dove, però, il giureconsulto provinciale aveva voluto semplicemente alludere, parlando di ius commune, al complesso delle istituzioni giuridiche che i popoli del bacino mediterraneo avevano in comune, e di fronte al quale lo stesso diritto romano era uno ius proprium, appunto come il diritto particolare della civitas romana.../I

CALASSSO FRANCESCO, Ob. Cit. Pp. 373- 374. Se destaca en ese entonces, que la forma de relación es diversa según la perspectiva, pues visto desde Roma el derecho romano es un derecho común a todo el Imperio, mientras que visto desde fuera de Roma, el derecho romano resulta un derecho propio a Roma.

${ }^{20}$ La Escuela de Bolonia, alma mater de todas las facultades jurídicas del mundo, nace a finales del siglo XI y comienzos del XII, por obra de Irnerio, maestro de artes liberales, que de gran intuición: da a la enseñanza del derecho aquel puesto autónomo que inicialmente no era reconocido. La recomposición y estudio de los textos jurídicos de Justiniano representan el contenido de estudio.

${ }^{21}$ El Liber Extra del Papa Gregorio IX marca el inicio de un nuevo método en la historia de las fuentes del derecho de la Iglesia, similar al método utilizado 
Se puede decir que la historia del derecho, en la era del derecho común, es una historia más política que jurídica, donde la historia jurídica sigue un binario y la historia política condiciona sobre otro binario la historia jurídica. El verdadero problema de relación entre derecho común y derecho propio era político ${ }^{22}$.

El derecho común que nace en Bolonia, reunirá a alumnos de diversas partes de Europa, entre ellos españoles, quienes posibilitan la expansión del lus commune ${ }^{23}$.

En España, vemos importantes focos del ius commune, como son las universidades de Valladolid y Salamanca. La universidad de Palencia que fue elegida en Castilla como la universidad de referencia de la Península Ibérica a fines del siglo XII24.

Junto con las universidades que portan el derecho común a España, está la voluntad de la Monarquía que quería disminuir el derecho propio, se ha buscado de atenuar, en realidad el Monarca quería cancelar la realidad de los fueros ${ }^{25}$.

En 1265, el rey Alfonso X, el Sabio, promulga la ley de las Siete Partidas, la que fue escrita en castellano, con fuentes romanas y canónicas, representando la máxima expresión del derecho común en España ${ }^{26}$. Ciertamente no era el derecho

por Trivoniano en la elaboración del Código de Justiniano. Esta obra, en gran parte, se debe a Raimundo de Peñafort, santo español, estudiante en Bolonia, graduado en Utrumque lus que sirvió como capellán y penitenciario al Papa Gregorio IX.

${ }^{22}$ Mientras que entre derecho común y derecho propio civil la relación era dialéctica, los dos bloques, derecho común y derecho propio, eran diversos y según la relación política, se ponen en diversas situaciones, pues el derecho propio de las ciudades comunales se encuentran con el derecho imperial por un presupuesto teórico, dado que las ciudades comunales no reconocían al Emperador como su superior, no reconocen así al derecho del Emperador; En cambio para la Iglesia es todo diverso, el derecho propio de la Iglesia estaba en total sintonía con el derecho común. El Papa más allá de ser la autoridad religiosa, es también legislador, para una parte de territorio rey temporal. En tal sentido, la relación en el ámbito de derecho canónico, entre derecho común y derecho propio era muy lineal.

${ }^{23} \mathrm{El}$ jurista francés Rene David al respecto refiere: -...l/ mezzo principale che ha permesso alle nuove idee di espandersi, favorendo la rinascita del diritto, è stato costituito dai nuovi focolari di cultura creati nell'occidente europeo; un ruolo essenziale appartiene alle università, prima o più illustre delle quali è stata, in Italia, I'università di Bologna...|| DAVID RENÉ- JAUFFRET SPINOSI J. I grandi sistemi giuridici contemporanei. CEDAM. Padova 1994. Pp. 32

${ }^{24}$ Señala el profesor Calasso: - ...Ma già nella stessa Spagna nascevano le università, organizzate a imitazione dello Studio bolognese, a cominciare da quella di Salamanca, fondata nel 1220 da Alfonso IX. La cultura giuridica spagnola era fortemente imbevuta, dunque di dottrina italiana; no altrettanto il mondo della prassi...|| CALASSO FRANCESCO, Ob. cit. Pp. 615616.

${ }^{25}$ En relación al interés político de la monarquía señala el profesor español José Sánchez- Arcilla: -... La equiparación del poder real al poder imperial implicó la asunción por parte de los reyes de las prerrogativas reservadas por el derecho romano a la majestad del emperador y el configurar su poder de acuerdo a los principios absolutistas que presidían los textos justinianos...SÁNCHEZ-ARCILLA BERNAL JOSÉ, Historia del Derecho Español. Manuales Básicos. Cálamo, Producciones Editoriales, S.L. Segunda Edición. Barcelona 2005. Pp.187

${ }^{26}$ Sobre las fuentes de las Partidas o - Libro del Fuero de las Leyes/| señala Sánchez- Arcilla: -... Se han identificado algunos textos del derecho canónico (el Decreto de Graciano y las Decretales de Gregorio IX), las fuentes romanas de la Partida $1^{a}$ y las de alguna institución concreta ...Igualmente se han identificado las fuentes en materia de derecho feudal... Los redactores de las Partidas fueron reacios a dar referencia de las fuentes utilizadas. En común de Bolonia, pero era una revivificación del derecho común que entró como ley subsidiaria ${ }^{27}$.

Notable también es en el año 1348, el Ordenamiento de Alcalá, promulgado por Alfonso XI en el cual se estableció la jerarquía de las fuentes del derecho: al primer lugar la ley del Reino, luego la ley de los fueros y sucesivamente la ley de las Siete Partidas ${ }^{28}$.

Cabe la pena destacar que "... Ni los glosadores ni los comentaristas hicieron aportaciones de interés acerca del concepto de derecho. Por el contrario, fue santo Tomás quien, desde el campo de la teología, aportaría una nueva concepción acerca de la ley y del derecho que acabaría teniendo importantes repercusiones en el campo del pensamiento jurídico a partir del siglo XVI...// ${ }^{29}$.

Es así que, con la reconquista y el descubrimiento de América, España no sólo crece en unidad política y religiosa, sino que crece también en su unidad jurídica.

\section{d) Los factores que impulsaron la conquista del Perú}

Como referimos anteriormente, luego del descubrimiento de América, España contaba con una -legitimación// para la conquista de nuevas tierras con la dación de las Bulas Pontificias de Alejandro VI, que posteriormente fue delimitada en el Tratado de Tordesillas; Además, Iogrando

cualquier caso, se pueden distinguir fuentes jurídicas y las no jurídicas. Dentro de estas últimas, además de la Biblia y de escritos de la patrística (san Agustín, Santo Tomás), se citaban también autores paganos.../I SÁNCHEZ- ARCILLA JOSE, La obra legislativa de Alfonso X, el sabio (I). Revista General de Legislación y Jurisprudencia. № 1. Editorial Reus. Madrid 2003. Pp. 113.

${ }^{27}$ Muy interesante resulta la consideración y relación entre persona humana y ser humano. De ello Citando a Garcia Gallo señala Gonzales: - ... Es sabido que en línea del Derecho romano, el Derecho de Castilla a comienzos del siglo $X V I$, mantiene la referencia concreta al ser humano a través de la noción -homoll u -hombrell, la misma que se identifica plenamente con la de - persona/|...// GONZALES MANTILLA GORKI, La miserabilidad del indio en el siglo XVI. Revista de Derecho Themis. Pontificia Universidad Católica del Perú. Segunda Epoca. № 34. Lima 1996. Pp. 291. Cit. GARCIA GALLO, A., Estudios de Historia del Derecho Privado. Universidad de Sevilla. Sevilla 1982. Pp. 44 Añade Gonzales: -... La definición otorgada por las Siete Partidas es clara. Al lado del reconocimiento del hombre como expresión que indica el estado natural de todos los seres humanos, libres, siervos y libertos, nacidos o por nacer (partida IV.23), se encuentra el uso de la palabra - personall, para indicar la referencia concreta al hombre que en cada caso actúa en la vida jurídica (...) La afirmación de la naturaleza humana del indio, es decir, su condición de persona implícita, se ratifica en este contexto.../I GONZALES MANTILLA GORKI, Ob. Cit., Pp. 292.

${ }^{28}$ Añade Sánchez- Arcilla: -... Ello supuso el triunfo definitivo del ius commune sobre el derecho tradicional municipal, pues, aunque en el orden de prelación se anteponía - si bien con algunas limitaciones- la alegación del derecho municipal a las Partidas, al concedérsele el carácter legal (-damolas por nuestras leyes/|), dado que hasta entonces no habían sido - avidas nin rescibidas por leyes\|, los juristas interpretaron que éstas debían de aplicarse en cuanto -leyes/l en primer lugar y, por tanto, antes que el derecho municipal...// SÁNCHEZ-ARCILLA BERNAL JOSÉ, Historia del Derecho Español. Ob. Cit. Pp. 226.

${ }^{29}$ Ibídem. Pp. 195 Refiere el profesor Calasso: -...tutte le artificiose limitazioni che vennero poste dal potere regio ai giuristi rimasero letrera morta, mentre la Spagna si preparava a vivere, nel secolo XVI, un proprio rinascimento giuridico, costellato da grandi nomi di giureconsulti.../ CALASSO FRANCESCO, Ob. cit. pp. A esto es necesario añadir que la reflexión sobre el derecho realizada por Santo Tomás de Aquino es complementaria a la reflexión sobre la persona humana, que brinda propiamente el sustento y la base del concepto de ley y derecho. 
cierta unidad en el derecho, reflejo de la unidad política, España resultaba así preparada para la conquista a las tierras de los Incas.

Sin embargo aquella conquista casi realizada 40 años después del descubrimiento de América, estuvo precedentemente enumerada de algunos factores que valen la pena referir.

Desde un punto de vista político, convertida ya en una Monarquía, España representaba una de las primeras naciones de Europa. De modo especial, en 1519 el rey español Carlos I, es elegido emperador del Sacro Imperio Romano Germánico, convirtiéndose así en una de las principales figuras de la edad moderna ${ }^{30}$. Este país ibérico, lograría luego la conquista de dos de los más famosos imperios precolombinos de América: el de México (Azteca) y el del Perú (Inca) ${ }^{31}$.

Desde lo económico, con el descubrimiento, conquista y colonización del Nuevo Mundo, se inició una intensa actividad comercial, donde España aprovechó de estos territorios, principalmente, las numerosas riquezas consistentes en minerales como el oro y la plata, así como metales preciosos. De ello se explica la creación en 1503 de la Casa de Contratación de las Indias, entidad encargada de controlar el comercio con las nuevas tierras, tanto en el aspecto fiscal con el pago de impuestos, como en el aspecto técnico con las cartas de navegación o formación de pilotos.

En la perspectiva científica, un instrumento muy valorado por los conquistadores fue la brújula, por su orientación en los pasajes marinos de exploración de los territorios americanos. Corresponde a este tiempo el conocimiento del Océano Pacífico ${ }^{32}$, y luego la hazaña de la navegación girando el mundo entero ${ }^{33}$.

Respecto a lo militar, un factor importante era que los hispanos contaban con armas y con un conocimiento bélico avanzado. Los años previos habían adiestrado a los conquistadores a entender las reacciones bélicas de los nativos.

\footnotetext{
30 La Monarquía Española constituyó un extenso territorio, cuando la concentración en la persona del rey de España Carlos I y al mismo tiempo emperador del Sacro Imperio Romano Germánico Carlos V, de cuatro grandes dinastías: la castellana y las Indias (por herencia de la abuela materna, Isabel I la Católica), la aragonesa (por herencia de su abuelo materno, Fernando II el Católico), la de Borgoña y los Países Bajos (por herencia de su abuela paterna, María de Borgoña), y la de la Casa de Habsburgo con el Sacro Imperio Romano Germánico (por herencia de su abuelo paterno, el emperador Maximiliano I)

3129 Los españoles, previo a la conquista peruana, ya tenían fundados las ciudades de La Española (1492), Santo Domingo (1496), Baracoa - Cuba (1512), Tenochtitlán- México (1521), San Juan- Puerto Rico (1521), Guatemala y El Salvador (1523- 1524), Santa Marta- Colombia (1525)

${ }^{32}$ En 1513 el descubridor español Vasco Núñez de Balboa descubre el océano Pacífico.

${ }^{33}$ Aquella expedición iniciada en 1519 por el navegante portugués Fernando de Magallanes, que posteriormente fue completada por el español Juan Sebastián Elcano en 1522, resulta el primer viaje de circunnavegación del globo terráqueo.

${ }^{34}$ Este sistema, duramente combatido por el Padre dominico Antonio de Montesinos, quien lanzó un sermón en la isla de La Española contra el uso de la encomienda y el mal trato de los indios: "¿Cómo los tenéis tan oprimidos y fatigados, sin darles de comer ni curarlos en sus enfermedades, que de los excesivos trabajos que les dais incurren y se os mueren, y por
}

Desde un punto de vista social y jurídico, ya en algunas ciudades se habían implantado el sistema de la encomienda ${ }^{34}$. La polémica sobre el mal trato a los indios americanos, cuestiona a la corona española, es por ello que el rey Fernando II publica en 1512 las denominadas Leyes de Burgos, primer cuerpo legislativo promulgado en exclusiva para el Nuevo Mundo, y cuyo objeto era mejorar el trato dado a los indios de parte de los colonizadores, aligerar sus obligaciones laborales, regular sus condiciones de vida, y de modo especial, velar por su evangelización y educación. No obstante, el sistema de la encomienda no fue cuestionado. Serán las leyes de Burgos, una de las bases del Derecho Indiano, como posteriormente analizaremos.

Finalmente, y no por ello menos importante, desde el punto de vista religioso, el extraordinario interés de la Iglesia Católica por la difusión de la fe es notable. No fueron pocos los mártires que supieron bien trasmitir la catolicidad a los nativos del Nuevo Mundo ${ }^{35}$.

En suma, aquello que es evidente es que la magnitud de la empresa asumida por los españoles fue enorme. Una tarea que, en el tiempo, desbordaba a las posibilidades de cualquier otra potencia Europea. Entre luces y sombras, propio de todo acontecimiento histórico, los objetivos perseguidos por la Corona tuvieron en todo momento un doble carácter: material y espiritual. Con la particularidad que, desde la Corona, se procuro que ese beneficio no se lograra en perjuicio de los intereses de los nativos andinos.

\section{LA SÍNTESIS CULTURAL: EL NACIMIENTO DE LO MESTIZO}

Las posiciones de los historiadores sobre el descubrimiento, conquista y colonización del Perú, son muy diversas.

No obstante de esta variedad, aquello que interesa destacar es la síntesis de este encuentro entre lo incaico y lo hispano. Síntesis que más de responder a un factor ideológico o subjetivo, responde a un hecho claro y objetivo ${ }^{36}$. Este hecho objetivo se enfatiza con el nacimiento de una nueva raza, de

mejor decir los matáis, por sacar y adquirir oro cada día?.... ¿Estos no son hombres? ¿No tienen ánimas racionales?". DOIG GERMÁN, Ob. Cit., Pp. 92 ${ }^{35}$ Señala Abellán: - ...La presencia eclesiástica en Iberoamérica no fue sólo una mera presencia institucional, relacionada con el mundo de las creencias religiosas y su organización estructural desde la jerarquía. Muchos eclesiásticos, en cuanto individuos, contribuyeron con sus planteamientos intelectuales rigurosos y amplios al desarrollo de ciencias inéditas hasta entonces, $y$ en este aspecto el balance es claramente positivo. Un conjunto de actitudes intelectuales profundas y serias llevó a un pequeño pero glorioso grupo de frailes, misioneros y sacerdotes a aceptar el reto que la realidad americana les imponía... ABELLÁN JOSÉ LUIS, Ob. Cit., Pp. 744.

${ }^{36}$ Señala el historiador peruano José De la Puente y Candamo: - Una primera idea es objetiva y sencilla. La llegada de Colón a este continente, pertenece a nuestra vida como parte de nuestro pasado. A menudo los peruanos olvidamos una afirmación elemental; todo lo que ha sucedido y sucede en nuestro territorio, nos pertenece, grato o no, justo o indebido; hay una solidaridad profunda que no podemos desconocer, ni rechazar, sin mutilar nuestra propia personalidad (...) solidaridad no significa acuerdo, aprobación o complacencia con lo que ha sucedido; significa sí, reconocer que ese pasado nos pertenece, nos ha creado, con sus aciertos y errores. Se trata, en fin, de un reconocimiento de la realidad (...) No debemos recrear el pasado de acuerdo con nuestros modelos subjetivos; no debemos crear una historia de lo que pudo ser y no fue...DE LA PUENTE Y CANDAMO JOSÉ A., La identidad peruana en lo hispanoamericano. Colección Algarrobo № 36 . ADEU. Universidad de Piura. Piura- Perú. 1992. Pp. 18- 19 
una nueva cultura, de una nueva historia, de una nueva identidad, como es la mestiza.

La captura del inca Atahualpa en 1532 por Francisco Pizarro en Cajamarca, más allá de un hecho histórico, representa el encuentro de dos mundos, el encuentro de dos culturas con sus propias tradiciones y características.

Este mutuo hallazgo, enriquecido y mejor entendido con el pasar de los años, guarda tanto para los españoles como para los indígenas un profundo diálogo. De una parte para los hispanos el conocer, sólo por mencionar algunos aspectos, en el Imperio Inca una organización política, social y cultural, conocer una geografía muy diversa y hermosa, conocer una riqueza en productos alimenticios, ganaderos y minerales. De otra parte para los indígenas, el conocer la religión Católica y la fe unida a los valores que ésta comporta, conocer la escritura, conocer una nueva cultura, la del mundo occidental del siglo XVI, que comporta un modo de vida organizada política, social y económica diferente.

Un aspecto que es necesario señalar, es que el Perú nace a partir de la llegada de los españoles, antes de eso lo que existía era el Tahuantinsuyo, el imperio inca. Así mismo, no sería correcto referirse al Perú solamente como una colonia hispana sin hacer referencia al pasado: al Imperio Incaico y a las culturas pre incas. Con esto se destaca que la conquista de 1532 no representa el fin del mundo andino, sino más bien su transformación, se enriquece sin dejar de ser andino ${ }^{37}$.

-...El Perú, como otros países de América, es un crisol en el que se han venido a fundir dos razas, la indígena y la española, a las cuales posteriormente se agregaron la raza negra y otras traídas por la inmigración. De la fusión de todas y, especialmente, de las dos primeras, va surgiendo el peruano, que no es ni español, ni indio, sino a lo más mestizo...// ${ }^{38}$.

Con este encuentro de dos mundos, se pone de manifiesto un confronte, con aspectos positivos y negativos, que representa el mutuo aprendizaje de una cultura de otra, situación que se extiende y conserva con el pasar de los años.

Este encuentro marca la historia peruana, le brinda una nueva identidad que no es la incaica o pre hispana, ni tampoco es la

${ }^{37} \mathrm{Al}$ respecto, señala De la Puente y Candamo: -... El Perú, contra lo que manifiestan algunos autores, no pierde su autonomía en Cajamarca; desaparece la organización social y política que es el Incario, mas, el hombre andino participa de modo central en la formación de la sociedad peruana naciente. Una consideración puede aclarar mejor la idea. Los Incas, y el mundo milenario anterior, son parte irrevocable del Perú, pero aún no aparece el Perú. El Perú no se explica sin los Incas; del mismo modo que no se explica sólo con los Incas. El Perú es incaico y español al mismo tiempo. Con la conquista española pierde su autonomía el Incario, no el Perú, que aún en 1532 no existe (...) Este es el derrotero para conocer la identidad del Perú en su realidad mestiza. No es verdad lo que tanto se reitera, por ignorancia de la historia, y sostiene que el Perú carece de propia identidad. El nuestro no es un país inconsistente, amorfo, sin personalidad. Muy al contrario; viene de muy respetables y altas culturas con raíces milenarias, que en un largo y difícil mestizaje, especialmente complejo por la antigüedad y densidad de los componentes, crea una sociedad nueva con propia naturaleza y estilo...// Ibídem. Pp. 36- 37.

${ }^{38}$ VARGAS UGARTE RUBÉN, Historia de la Iglesia en el Perú, Ob. Cit. Pp. 26 ${ }^{39}$ DE LA PUENTE CANDAMO JOSÉ AGUSTÍN, Reflexiones sobre la identidad Nacional, Ob. Cit. Pp. 46.

${ }^{40}$ El profesor Borges, en relación a la promoción individual de los indígenas realizada por los misioneros, señala: “...Fomentar en los indígenas su conciencia de hombre y en defender ante los demás esa misma cualidad. (EI española, es la mestiza, es la síntesis consecuencia de este primer encuentro de 1532.

-... Hoy día no es raro escuchar opiniones sobre la ausencia de dicha identidad o interpretaciones equivocadas de la misma. Frente a esta situación es importante recordar lo que se reitera en estas páginas: es decir, que el Perú es fruto de una historia de integración de sangres y de culturas, y que esa integración define lo nuestro y señala nuestra identidad. Esta es la verdad que la historiografía confirma; lo repito una vez más: la historia ha creado nuestro país por el camino de la síntesis, difícil pero cierta....// ${ }^{39}$

La formación de esta síntesis cultural, planteaba en sus inicios muchas interrogantes, una de las principales era ¿si el indio peruano era persona humana o no? La respuesta a esta interrogante plantea luego un cuestionamiento ético para los hispanos sobre la conquista. La reflexión sobre estos puntos, es muy rica en su contenido, y sirvió de base no sólo para problemas y situaciones jurídicas del siglo XVI, sino como inspiradores para posteriores documentos sobre derechos humanos, como veremos a continuación.

\section{a. La reflexión sobre el indio peruano: primero hombres y luego cristianos}

Con el encuentro de estos dos mundos, surgen entre los hispanos diversas valoraciones sobre los indios peruanos.

Sin dejar de reconocer los abusos y las injusticias que muchos nativos sufrieron, interesa destacar el principio, cuya motivación no sólo fue a nivel religioso, sino que alcanzó también relevancia jurídica.

El principio y la consideración que el indio peruano antes de ser cristiano, necesitaba primero ser reconocido como hombre, como ser humano, como persona humana ${ }^{40}$.

Esta reflexión, impulsada por los misioneros, reconocía la naturaleza racional del indio peruano como unidad de cuerpo y alma, a su vez entendía que el nativo no se comportaba del todo como persona humana debido a su estado cultural ${ }^{41}$. La transculturización como efecto de esta consideración, significó en teoría apartar a los nativos de las costumbres

primer Concilio de Lima, por ejemplo, ordenó en 1551-52 que se comenzara a catequizar a los indígenas haciéndoles ver su condición de hombres y su diferencia de los animales. Compartiendo esta mentalidad, algunos catecismos americanos no comienzan preguntando quién es Dios ni qué es ser cristiano, como nuestros clásicos Astete y Ripalda, sino que qué es ser hombre y por qué lo eran los indios)..." BORGES PEDRO, Ob. Cit. Pp. 526.

${ }^{41}$ Conviene recordar que sólo en 1537, por la bula Sublimis Deus de 9 de junio, se reconoce por una autoridad mundial que los indios tenían la misma condición humana que los habitantes del viejo mundo y que por tanto tenían la misma capacidad para ejercer y para disfrutar los mismos derechos que los que así llegaron; además se declara como cosa de fe que los indios son verdaderos seres humanos como los demás hombres, destinados por tanto a la salvación eterna y a los que deben proporcionar los mismos medios para conseguirla...RODRIGUEZ MOLINERO MARCELINO, La Doctrina Colonial de Francisco de Vitoria o el derecho de la Paz y de la Guerra. Un legado perenne de la Escuela de Salamanca. Librería Cervantes. Salamanca 1993 Pp. 41- 42. Añade Pedro Borges: -... Ni que decir tiene que la Iglesia no admitió, ni podría admitir, la tesis de la irracionalidad del indio y de su consiguiente incapacidad para la fe. En tal caso no hubiera procurado su evangelización ni se hubiera preocupado de sus problemas...// BORGES PEDRO, La Iglesia americana y los problemas del indio. BORGES PEDRO (Dir.), Historia de la Iglesia en Hispanoamérica y Filipinas (Siglos XV-XIX) Volumen I: Aspectos Generales. Biblioteca de Autores Cristianos. Madrid 1992. Pp. 664 
contrarias a la naturaleza y al cristianismo, en conservar las buenas o aquellas indiferentes y en sustituir las primeras y complementar las segundas con las propias de la civilización europea; en la práctica representó, una compleja dificultad, por la diversidad de las costumbres, ya que la transformación a la que aspiraban los evangelizadores no era un concepto unívoco que evitase interpretaciones divergentes.

-...El carácter sustitutivo de la transculturación consistió en que no se trató de la simple destrucción o desaparición de unas culturas, sino de la sustitución de una variada serie de culturas por otra. En términos de evolución histórica, los que los misioneros hicieron fue lograr a los dos o tres lustros de su llegada a un territorio americano determinado lo que la humanidad más avanzada había tardado en conseguir varios millares de años: evolucionar del paleolítico en la mayor parte de casos, o del neolítico en algunos de ellos, al estadio cultural europeo de los siglos XVI, XVII, XVIII o XIX, según el momento $y$ el territorio de que se trate... $/{ }^{42}$

En este período, ante los abusos e injusticias sufridas por los indios peruanos, uno de sus más tenaces defensores fue Bartolomé de las Casas. Refiriéndose a una de sus obras titulada Historia Apologética señala Lewis Hanke: -...En esta curiosa e interesante obra antropológica, Las Casas revela una intuición para estudiar culturas ajenas...., trata de comprender la importancia de las costumbres y creencia de éstos dentro de su propia cultura.... Las Casas considera a todos los pueblos, a los antiguos griegos, los tártaros

salvajes y los españoles del siglo XVI, lo mismo que a los nativos del Nuevo Mundo, como seres humanos en diferentes estados de desarrollo, desde los rudos comienzos hasta un grado más elevado de cultura....// ${ }^{43}$

\section{b. Los cuestionamientos éticos de la Conquista: el} aporte de Francisco de Vitoria

Las conquistas de los imperios aztecas e inca, completada en 1532, habían modificado en los hispanos la visión inicial de los

42 BORGES PEDRO, La Iglesia y las culturas prehispánicas. BORGES PEDRO (Dir.), Historia de la Iglesia en Hispanoamérica y Filipinas (Siglos XV-XIX) Volumen I: Aspectos Generales. Biblioteca de Autores Cristianos. Madrid 1992. Pp. 673.

${ }^{43}$ HANKE LEWIS, Bartolomé De las Casas, historiador. Estudio preliminar. MILLARES CARLO AUGUSTIN (edit.) Historia de las Indias por Fray Bartolomé De las Casas. Fondo de Cultura Económica. Segunda Edición. Mexico D.F.1965. Pp. 14. Sobre De las Casas, señala González- Fernández: - ...La visione manichea di Las Casas sulla scoperta e sulla conquista (tutti gli scopritori e conquistadores sono statu diabolici, mentre tutti gli indios erano buoni e innocenti) è stata accettata da molti acriticamente come fonte per giudicare la conquista ed elaborare la -leyenda negra/|.../ GONZÁLEZ FERNÁNDEZ FIDEL, La coscienza cristiana e i problemi della conquista nella formazione dell'America latina. Cardini Franco (a cura), Processi all Chiesa. Mistificazione e Apologia. Piemme 1994. Pp. 286

${ }^{44} A$ diferencia de lo sucedido con Hernán Cortés en Nueva España, la conducta de Pizarro en el Perú constituyó un verdadero escándalo, reflejado en el disgusto del emperador por la muerte de Atahualpa, comunicado en 1535 al cabildo de Lima por el dominico Tomás de Berlanga.... La conquista del Perú y más concretamente el ajusticiamiento de Atahualpa, constituyó una especie de sacudida de las conciencias que dio lugar al nacimiento de una clara corriente antibelicista... BORGES PEDRO, La Iglesia americana y los problemas del indio. Ob. Cit., Pp. 657.

${ }^{45}$ DOIG K. GERMÁN, Ob. Cit. Pp. 90. Lo mismo es sostenido por Lohmann, quién señala: -...No es frecuente que la Historia ofrezca ejemplos en que el vencedor sienta compasión por el vencido, cuánto menos aún que lo haga pueblos americanos descubiertos, en cuanto reconocían a hombres con cierta cultura, expresada en sus construcciones, sus modos de organización social y política.

La conquista del Perú es uno de los eventos de mayor importancia en la historia del Perú así como también uno de los más sobresalientes eventos de la historia del Nuevo Mundo.

Con la captura, el rescate y la muerte del inca Atahualpa, comienza una serie de cuestionamientos de parte de los hispanos sobre la ética de la conquista ${ }^{44}$.

-...Cabe destacar como un hecho muy importante para el desarrollo del tema de los derechos del hombre, que se trata del único caso en la historia de la humanidad en el que el conquistador cuestiona la condición ética de su presencia y se obliga a legislar en favor de los pueblos sometidos en la búsqueda de un modus vivendi de acuerdo con los principios del derecho natural...// 45

Distintos son los argumentos que se cuestionan a la conquista española, entre éstos tenemos: a) La apropiación de los territorios y riquezas de los indígenas. La distribución de las tierras andinas, la organización política que cambió el Imperio Incaico por un sistema gobernado por españoles, el codiciado interés hispano por los minerales peruanos b) La religión como instrumento de la conquista, algunos historiadores señalan que las culturas pre hispanas adoraban a dioses como el sol, la luna, las montañas, los animales, entre otros; con la conquista, algunos hispanos impusieron la religión católica, privando a los indígenas de sus creencias primigenias. c) el exterminio de los indios andinos, algunos historiadores señalan que de una población de doce millones de habitantes, 45 años después, se redujo a sólo un millón de indios.

Diversas son las causas atribuidas: muchos atribuyen a enfermedades y epidemias. Otra va en relación a los trabajos forzados e impuestos desproporcionados que explotaban y empobrecían a los indios ${ }^{46}$.

objeto de su apología, y todo ello sin merecer un gesto de correspondencia por la colectividad tan ardorosamente defendida..../ LOHMANN VILLENA GUILLERMO, Propuestas de solución de juristas y políticos. PEREÑA LUCIANO (dir.) Francisco De Vitoria y la Escuela de Salamanca. La ética en la conquista de América. Consejo Superior de Investigaciones Científicas. Volumen XXV. Madrid. 1984. Pp. 632. Luego añade Lohmann: -...Probablemente en ninguna otra comarca del Nuevo Mundo subsistía una sucesión reconocida de los soberanos prehispánicos, o sea que lo que en cualquier lugar era una simple especulación, en el Perú se convertía en una contingencia que en modo alguno cabía como utópica...// Ibídem Pp. 644

${ }^{46}$ Sin desconocer los sufrimientos del hombre andino al vivir en un mundo que declina y al asistir y participar en la gestación de formas nuevas de existencia, tampoco puede omitirse lo que es y significa el ingreso consciente a la geografía y a la historia universal (...) ¿Habría sido mejor para el hombre andino que no se realizara el descubrimiento de Europa y que continuara su aislamiento, encerrado en sí mismo, como creen algunos autores? En primer lugar, la respuesta no es posible, pues pertenece en el campo de la ficción que no se puede trabajar; en todo caso es el terreno de la utopía, no de la historia. ¿Acaso, por afirmar y defender formas originales del Tahuantinsuyo, puede postularse seriamente que habría representado para ese hombre un mejor destino, la perennidad del aislamiento? Sin duda, el solo contacto con los hombres de otros rumbos de la tierra, ya es un valor; sin olvidar las injusticias, los sufrimientos, los abusos. No se desconoce la posible felicidad cotidiana del hombre en el Incario, mas, era una felicidad recortada, pues vivía aparte de calidades y virtudes que ignoraba. (...) No desconocemos - antes lo digo - los errores, injusticias, abusos. Más, 
-...Pero sería carecer de todo sentido humano y de todo criterio de relativismo histórico juzgar estos hechos como si se hubieran realizado de un medio diverso y en circunstancias distintas de aquellas que lo rodearon. Justo sería comparar la orientación espiritual de empresas semejantes realizadas por otros pueblos. El valor territorial y el valor riqueza predomina en estas sobre el valor hombre; en cambio, en medio de sus errores y de sus deficiencias, el valor hombre fue la preocupación de la conquista española. Desdén y aniquilamiento inspiraban las tribus primitivas a los conquistadores de otros imperios; simpatía humana y sentido de aproximación inspiraron las tribus primitivas no sólo a los misioneros, sino a los mismos conquistadores españoles quienes no desdeñaron unir su sangre con la sangre aborigen. Esta profunda preocupación humana y ética, fracasada muchas veces y contrariada otras por el curso fatal de los hechos, es el alma de la Conquista, es su esencia, es el legado que nos ha transmitido y que constituye el factor decisivo de la Peruanidad.... Se puede decir, empleando en su hondo significado el concepto y término teológico de asunción, que la cultura católica asume las tierras y las poblaciones de América infundiéndoles un nuevo espíritu.... - 47

Un aporte sustancial a la reflexión sobre la ética de la conquista, es atribuida al teólogo español Francisco De Vitoria y a la Escuela de Salamanca que él fundo ${ }^{48}$.

- El centro neurálgico de dicha concepción antropológica es el concepto de persona humana, considerada como ser racional, libre, moral y responsable, con su correspondiente traducción jurídica de sujeto de derechos morales innatos...//49.

tampoco se puede olvidar los valores que ingresan a nuestra historia y se convierten en propios...// DE LA PUENTE Y CANDAMO JOSÉ A., Ob. Cit., Pp. 20-22. Añade González- Fernández: - ...La conquista fu dura e a volte anche violenta, non meno che le guerre che insaguinavano l'Europa dell'epoca, ma subito in America nacque una volontà ben precisa di mettere fine a quel grave disordine, e questo per grazia della coscenza cattolica... GONZÁLEZ FERNÁNDEZ FIDEL, Ob. Cit., Pp. 297.

${ }^{47}$ BELAUNDE VÍCTOR ANDRÉS, Peruanidad, Pontificia Universidad Católica del Perú. Instituto Riva-Agüero, Lima 1968. Pp. 34- 35.

${ }^{48}$ Refiere Rodríguez Molinero: -... Una de las aportaciones más brillantes y singulares de la Escuela de Salamanca, que la distingue precisamente de la labor de los demás autores hispanos y también de los castellanos, fue su valiente y novedosa postura ante el difícil problema de la conquista y posterior anexión por el poder regio de los entonces llamados pueblos insulanos o indianos. Frente a la tesis imperialista propalada con gran ruido por los juristas y letrados de la Corte y frente a la tesis teocrática propugnada por los teólogos que estaban a su servicio, los maestros de Salamanca, siguieron fielmente la doctrina de Francisco De Vitoria, defendieron los derechos inalienables de los pueblos indios, entre ellos a conservar sus propiedades y a mantener a sus gobernantes legítimos, así como a preservar sus lenguas y tradiciones... RODRIGUEZ MOLINERO MARCELINO, Ob. Cit., Pp. 22- 23 Añade el jurista peruano Francisco Rizo Patrón: -...El avance de la reflexión jurídica gracias al impulso de Vitoria y de la Escuela de Salamanca fue notable. La constante preocupación por la justicia y el derecho en los teólogos y juristas españoles influyó profundamente en el pensamiento jurídico. En las propuestas de éstos aparecen claramente elementos que posteriormente han quedado tipificados como derechos del hombre y otros que se pueden encontrar en las bases del moderno derecho internacional..../ RIZO PATRÓN FRANCISCO, El derecho público en el pensamiento de Francisco de Vitoria. Vida y Espiritualidad. Lima 1999. Pp. 15.

${ }^{49}$ ABELLÁN JOSÉ LUIS, Ob. Cit., Pp. 732. Al respecto refiere Hernández -...Dos perspectivas tendrá en cuenta Vitoria en la exposición de estos
Vitoria destaca la consideración sobre los indios americanos como seres racionales, como titulares de derechos y con capacidad jurídica. Esto conlleva a proclamar la igualdad de todos los seres humanos y el reconocimiento de sus derechos naturales basados en su dignidad.

-...Alla base delle sue opinioni si possono trovare fondamenti antropologici e metafisici, che non sono in contrasto con quelli positivi e storici, se si considera che nell'uomo c'è qualcosa che non può essere ridotto alla propria attività libera, espressione espansiva della sua dignità...// ${ }^{50}$.

-... Dall'incontro della nozione di humanitas con quella di persona, elaborata dalla filosofia scolastica, scaturisce il concetto di persona umana, predicabile di tutti gli uomini e indicativo della singolarità e irripetibilità dell'individuo umano, come assoluto, al di là di ogni relazione giuridica formalizzata e delle forme circostanziali di cultura e di contesto sociale. Sul piano giuridico, lo sviluppo di questa concezione di persona consente di stabilire formalmente rapporti giuridici al di sopra delle società particolari. Così nasce e si sviluppa per conto dei giuristi spagnoli del secolo XVI il diritto delle genti, un diritto che è riconoscimento dello statuto della persona umana...// ${ }^{51}$.

Reconociendo primero la personalidad y dignidad de los indios americanos, Vitoria luego desarrolla su reflexión sobre unos justos títulos.

Un primer aspecto es que la persona humana por su propia naturaleza es un ser social, tiene un derecho natural a la comunicación, por tanto se justifica un derecho a la comunicación entre los pueblos. Los españoles pueden ir a América sin hacer daño a los nativos, del mismo modo

derechos: una macrocósmica o internacionalista, que mira a las exigencias de los pueblos o sociedades civiles, y otra microcósmica o individualista, que se fundamenta en la dignidad de la persona humana con sus derechos inalienables...// HERNÁNDEZ RAMÓN, Las hipótesis de Francisco De Vitoria. PEREÑA LUCIANO (dir.) Francisco De Vitoria y la Escuela de Salamanca. La ética en la conquista de América. Consejo Superior de Investigaciones Científicas. Volumen XXV. Madrid. 1984. Pp. 362. Sobre el aporte de Victoria y la Escuela de Salamanca añade Pereña: -...Este proceso se caracteriza por la actitud común de los teólogos sobre la legitimidad de la conquista de las Indias en función de una misma comunidad de preocupaciones, de fuentes y métodos. La fe en el indio y en su capacidad de libertad define la nueve ética de la conquista. La humanización de las relaciones entre indios y españoles condiciona su moralidad. $Y$ el descubrimiento del indio como hombre y su razón histórica se constituye en el objetivo prioritario de su tratamiento metodológico...// PEREÑA LUCIANO, La anexión de América a la luz de la teología. BORGES PEDRO (Dir.), Historia de la Iglesia en Hispanoamérica y Filipinas (Siglos XV-XIX) Volumen I: Aspectos Generales. Biblioteca de Autores Cristianos. Madrid 1992. Pp. 635- 636

${ }^{50}$ TRUJILLO PÉREZ ISABEL, Francisco De Vitoria, /l diritto alla comunicazione e i confini della società umana. G. Giappichelli Editore. Torino 1997. Pp. 25. -... La sua opzione tomista l'ha condotto a costruire una morale della dignità umana, che ha la sua origine nella creazione ad opera di Dio, ma che corrisponde concretamente alle esigenze, ai diritti e ai doveri della natura umana. Questa morale della dignità umana si applica a tutti gli uomini nel rispetto della loro libertà e nella solidarietà; essa inoltre guida la condotta degli stati e dei governi, nonché le vicende delle relazioni internazionali../l Ibídem. cit. VEREECKE L., Da

Gugliemo d'Ockham a sant'Alfonso da Liguori. Saggi di storia delle teologia morale moderna. 1300- 1787. Paoline, Milano, 1990. Pp. 544- 545.

${ }^{51}$ Ibidem Pp. 91 
aplicado para los indios andinos. Sin hacer mención a dominio, sólo se refiere de un derecho natural ${ }^{52}$.

Señala Vitoria, refiriéndose a los títulos legítimos en su relección sobre los Indios:

-...El primer título puede nombrarse de la sociedad y comunidad natural... los españoles

tienen derecho de recorrer aquellas provincias y de permanecer allí, sin que puedan prohibírselo los bárbaros, pero sin daño a ellos.... Mas en todas las naciones se tiene como inhumano el tratar y recibir mal a los huéspedes y peregrinos sin motivo especial, $y$, por el contrario, es humanidad y cortesía el portarse bien con ellos, a no ser que los extranjeros reportaran daño a la nación....nunca fue la intención de las gentes evitar la mutua comunicación de los hombres...// 53

-...El ius societas et comumunicationis condiciona el nuevo concepto de la ética de la conquista. La vocación universalista y solidaria del hombre, que Vitoria cuidadosamente define, quiere ser la base - constitucionalll de la Nueva América. Partiendo de la -hominidadll de los indios, de su reconocimiento como hombres, el teólogo va definiendo y desplegando una serie de derechos y deberes políticos y sociales, igualmente comunes a colonizadores y colonizados. Su tesis se articula sobre tres principios claves: el derecho fundamental de los indios a ser hombres y a ser tratados como seres libres, el derecho fundamental de los pueblos indios a tener $y$ defender su propia soberanía, y el derecho fundamental del orbe a hacer y colaborar en bien de la paz y solidaridad internacional...// ${ }^{54}$

\footnotetext{
52 Francisco de Vitoria desarrolló una idea que ya existía, la idea del ius gentium, el -derecho de los pueblos|l, donde la palabra pueblos se asocia a la idea de -paganos||, de -no cristianos||. Se trata de una concepción del derecho como algo previo a la concreción cristiana del mismo, y que debe regular la justa convivencia entre todos los pueblos...// HABERMAS JURGENRATZINGER JOSEPH, Entre razón y religión. Dialectica de la secularización. RATZINGER JOSEPH, - Lo que cohesiona al mundo. Los fundamentos morales y prepolíticos del Estado liberalll Fondo de Cultura Económica, México D.F., 2008. Pp. 45- 46.

${ }^{53}$ DE VITORIA FRANCISCO, Derecho natural y de gentes, Emecé Editores, S.A. Trad. del latín por el P. Luis Getino, O.P. Buenos Aires Pp. 193- 194.

${ }_{54}$ PEREÑA LUCIANO, Ob. Cit., Pp. 639- 640

${ }^{55}$ Su análisis parecía irrefutable: el Papa no era Señor del Orbe ni podría nombrar príncipes de los indios a los Reyes de España. Tampoco el Emperador es Señor universal ni le correspondía la soberanía de las Indias por delegación del Papa. Injustamente - requerían/l los conquistadores a los indios y les obligaban por la guerra a reconocer y acatar la obediencia del Papa y del Emperador; ni tal dominio y expropiación de poderes se les podía demostrar con simples razones naturales y humanas...// Ibidem Pp. 638.

${ }^{56}$ Vitoria ritiene che coloro che sostengono che gli indios non siano sovrani delle loro terre si basino su tre motivi: i peccati degli indios, il fatto che siano infedeli e il loro essere -dementi o idiotill... La prima delle opinioni...., definita da Vitoria come - pura eresiall, era una radicalizzazione del soprannaturalismo medievale. Tuttavia, il maestro se ne servirà per esporre al positivo la nozione di persona come imago Dei. L'uomo è immagine di Dio per la sua natura razionale e non per grazia. Appartiene all'ordine naturale. In virtù delle sue capacità di raziocinio, l'uomo domina le sue azioni.... La capacità di dominare nell'uomo nasce dalla sua condizione personale: il dominare se stesso. Di conseguenza, nessun peccato (che glifa perdere i beni soprannaturali, ma non la sua condizione personale) può impedirgli di essere padrone dei suoi bene. L'indio americano, come qualunque altra persona, è sui iuris, ovvero possiede se stesso. Questo auto-possedersi, che lo rende partecipe del potere di Dio, gli permette l'esercizio legittimo della proprietà pubblica e privata. Se il peccato mortale non impedisce all'uomo l'esercizio del dominio, lo stesso avverrà per che è considerato infedele.... Resta da
}

En sus relecciones, Vitoria realizó una serie de cuestionamientos a los títulos de la conquista, parte desde la legitimidad de las Bulas Pontificias de Alejandro VI. Sin negar el poder espiritual del Papa en la Iglesia Católica, niega que el Papa tenga un poder temporal, esto resulta una cuestión histórica, no por revelación. Por eso el Papa no puede donar un territorio que no es suyo. Critica una teoría teocrática clerical que no distingue el orden temporal de lo espiritual. Tampoco corresponde a los Reyes ni al Emperador, pues estos territorios no eran parte de su Imperio. ${ }^{55}$

Según Vitoria los indios eran auténticos señores de su propiedad. Los hombres son personas con "capacidad de razonar, a su modo". Los indios son personas, tienen el uso de razón, tienen capacidad de dominio. Aún, sin importar la diversidad cultural, siendo infieles y no estando en estado de gracia, tienen derechos y no resulta éste el criterio de justificación del dominio hispano. ${ }^{56}$

Señala el profesor Vincenzo Buonomo: “... Infatti proprio nell'opera del De Vitoria si coglie l'originario delinearse di quanto la moderna espressione della dottrina internazionalista sintetizza nel principio della - autodeterminazione dei popolill, la cui indiscussa validità si è resa e si rende di primaria importanza nella normativa ed attività delle Nazioni Unite, ovvero nel più generale complesso delle relazioni internazionali... $/ /^{57}$

Vitoria reconoce el derecho a evangelizar como un derecho natural, a proclamar el Evangelio. Pero será un derecho fundamental de los indios a no aceptarlo. Todo ello es aceptable en términos pacíficos. Para ello es necesario el

analizzare cosa accade al diritto alla proprietà degli indios nel caso che questi fossero davvero da considerarsi come dementi o idioti. II maestro di Salamanca distingue fra essere il soggetto di alcuni diritti e ciò che concerne I'uso e l'amministrazione dei beni su cui il soggetto ha potere. II fatto che l'uso dei beni possa essere incidentalmente impedito, come nel caso di bambini ancora lontani dall'età della ragione o dei dementi, non è di per sé motivo sufficiente per negare la radicale dignità e uguaglianza di tutti gli uomini, essendo tutti ad immagine di Dio, esseri - con una personalità propria ed inalienabilell. Vitoria, inoltre, non ritiene che gli indios americani siano dementi. Mostrando, un'apertura mentale scervra da vision etnocentriche sorprendente per l'epoca in cui viveva, afferma che gli indios - essercitano, a modo loro, l'uso della ragione. Ciò è dimostrato dal fatto che organizzano le loro cose ordinatamente. Infatti vivono in città che richiedono ordine e hanno istituito matrimonio, magistrature, sovrani, leggi, artigiani, mercati; tutte cose che richiedono I'uso della ragione... ||..../ FAZIO MARIO, Due rivoluzionari: Francisco de Vitoria e Jean Jacques Rousseau. Armando Editore. Roma 1998. Pp. 52- 54.

57 BUONOMO VINCENZO, II Principio dell'autodeterminazione dei popoli in Francisco De Vitoria e nella attività delle Nazioni Unite. Studia Universitatis $\mathrm{S}$. Thomae in Urbe, I diritti dell'uomo e la pace nel pensiero di Francisco De Vitoria e Bartolomé De las Casas, Congresso Internazionale tenuto alla Pontificia Università S. Tommaso (Angelicum), Roma 4- 6 Marzo 1985. Massimo. Milano 1988. Pp. 228 Añade el profesor Buonomo: - ... La Scuola di Salamanca, il cui influsso varca gli stessi confini della Spagna, viene a costituire quindi la prima grande opposizione al colonialismo cosi come tale fenomeno si andava delineando (...) De Vitoria dà alla sua opera una prospettiva che pone in antitesi la prassi della conquista e i fondamentali principi della dottrina cristiana, così come la sintesi tomista medioevale li aveva delineati (...) Sostanzialmente il punto di vista di Francisco De Vitoria circa la libertà di ogni popolo da domini esterni resta spiegato dalla sua più ampia riflessione sulla presenza di una pluralità di entità statali, poste su un piano di paritaria sovranità tra loro.. ...Con il De Vitoria infatti si ha una prima teorizzazione di linee di condotta da attuare nelle relazioni internazionali, alla cui base sono posti i principi propri del diritti e della ragione naturale... Ibidem Pp. 229- 245 
buen testimonio de los misioneros, el buen trato a los indios, el hablar su lengua. Se subraya la libertad de los indios de convertirse o no, que representará un precedente de la libertad religiosa. ${ }^{58}$

Otros títulos expresarán la posibilidad de intervenir para salvar vidas de inocentes: la -injerencia humanitaria", que representará el presupuesto de la teoría del derecho internacional en este tema. Si el hombre es social por naturaleza, esto no se limita en un Estado, por tanto alcanza a toda la familia humana, de aquí la paternidad del De Vitoria en el derecho internacional. Por otro lado, considera el derecho a las alianzas, y además la tutela a los indios por parte de los españoles desde el punto de vista educativo. Un protectorado temporal español hasta que ellos puedan ser capaces del pleno uso.

Señala Doig: - ...Si bien no se elaboró propiamente un elenco de derechos como se conoce ahora, se estuvo muy cerca de hacerlo (...) El avance de la reflexión jurídica, gracias al impulso de Vitoria y de la Escuela de Salamanca, fue notable. Estos teólogos-juristas españoles influyeron profundamente en el pensamiento europeo y americano (...) Con toda justicia puede afirmarse que el Derecho Internacional tiene su origen alli... $\|^{59}$

A lo que añade Victor Andrés Belaunde: -...Las relaciones que la Conquista debía crear entre España y las razas del nuevo continente, plantearon no solamente varios problemas políticos e internacionales, sino otro, más profundo, relativo a los derechos del hombre, la igualdad de las razas humanas y la dignidad suprema de la persona.... De este escrupuloso y profundo planteamiento emergió triunfante el concepto de dignidad intangible e inviolable de la persona humana, cualesquiera fuesen la raza, la condición de cultura, la religión o la situación política en que los grupos humanos se hallaren... 60

\footnotetext{
58 Empezaron por reivindicar el derecho de los indios a la libertad de conciencia como base y punto de partida para encontrar una solución a la crisis de la Nueva Cristiandad.... Bajo su plena responsabilidad los indios debían decidir libre y voluntariamente el abandono de sus tradicionales creencias de acuerdo con su propia conciencia... La cristianización tenía que ir precedida de un proceso de humanización. Y esta humanización debía partir de su recuperación como hombres y como personas. El respeto de su libertad, la educación de esa libertad y la formación de la fe en la libertad constituían los tres requisitos o condiciones de cristianización de los indios.../I PEREÑA LUCIANO, Ob. Cit., Pp. 644- 645

59 DOIG K. GERMÁN, Ob. Cit. Pp. 94- 95.

60 BELAUNDE VICTOR ANDRÉS, La Síntesis Viviente. Ediciones Cultura Hispánica. Madrid 1950. Pp. 13-14.

${ }^{61}$ Memorable es el recuerdo de la Isla del Gallo (al sur de Colombia), los denominados trece del Gallo. Cuando en 1526, los españoles que partieron en busca de información sobre el Imperio Inca, atravesando grandes dificultades y desalientos recibieron la orden del gobernador de Panamá de ser repatriados. Pizarro se negó a regresar a Panamá derrotado, trazó una línea de oriente a occidente en la arena de la playa de la isla del Gallo, y dijo a sus compañeros: -Por aquí se va a Panamá a ser pobre; por allá, al Perú, a ser rico y a llevar la santa religión de Cristo, y ahora, escoja el que sea buen castellano lo que mejor estuvierell. Los castellanos que atravesaron la simbólica línea trazada por Pizarro, dieron una clara manifestación de que estaban dispuestos a todo.

${ }^{62}$ Las capitulaciones o-asientos/| no eran contratos como los pactados entre particulares. En ellas se insiste en que se trata de una-merced/| que
}

\section{c. El derecho indiano y la reflexión sobre el indio peruano}

Es conveniente señalar, antes de referiros al derecho indiano y a la reflexión sobre el indio peruano, evidenciar la sucesión de dos períodos históricos en la colonia hispana en el Perú: la conquista y el virreinato.

La conquista del Perú, nos muestra el testimonio de hombres valerosos y aventureros. Uno de ellos, sin lugar a dudas, fue el conquistador español Francisco Pizarro, quién previo a la llegada a tierras peruanas, había participado en el grupo fundacional de la ciudad de Panamá. ${ }^{61}$

En 1529 el rey de España Carlos I otorgó al conquistador español Francisco Pizarro la capitulación en la que era nombrado capitán general. La Capitulación de Toledo, como es conocida este documento, reconocía oficialmente a Pizarro como gobernador del Perú. ${ }^{62}$ Si bien en la Capitulación de Toledo se mencionaba al territorio andino como la Nueva Castilla, será llamado y conocido a las tierras incas con el nombre de Perú. ${ }^{63}$

La ocupación hispana en el Perú empezó con la fundación de la ciudad de San Miguel de Piura el año 1532, tuvo su punto neurálgico con la captura del Inca Atahualpa en Cajamarca en noviembre de 1532. Luego llegarán al Cuzco en 1534 y en 1535 se fundará la ciudad de Lima, conocida también como la Ciudad de los Reyes.

-...Pizarro comenzó a repartir indios desde que entró en el territorio de Nueva Castilla (lo que es actualmente el Perú), adelantándose quizás a la regia autorización ofrecida. Influían para apresurar el reparto las necesidades de la defensa del territorio que se iba ocupando. Con ese objeto había urgencia de fundar pueblos dejando en cada uno cierto número de españoles, y como éstos eran pocos y quedaban expuestos a los ataques de los indígenas, se hacía preciso, para que se resignasen a esa situación de aislamiento y peligro, recompensarlos con encomiendas. Así pues a los primeros

el rey otorga a petición del particular, con lo que la Corona aparece situada siempre en un plano de superioridad con respecto al solicitante; pero ello no es obstáculo para que ambas partes queden igualmente obligadas, con independencia de que en las capitulaciones se recojan órdenes que deben cumplir el capitulante, así como las mercedes que recibirá en caso de culminar su empresa con éxito... SÁNCHEZ- ARCILLA BERNAL JOSÉ, Ob. Cit., pp. 290. Las capitulaciones celebradas, no obstante de intervenir el Rey, se fueron desarrollando en la práctica dentro de un ámbito privado, como un negocio privado. La Corona Española dejará de financiar los viajes, y facilitará concesiones de viaje a los grupos de personas que acreditaran solvencia económica para seguir expandiendo las nuevas tierras del reino en América.

${ }^{63}$ Es interesante ver como el nombre de Perú corresponde a un vocablo mestizo, ya que no es ni un término quechua, aymara o español. Citando a Porras Barrenechea señala De la Puente: -El nombre del Perú no significa, pues, ni río, ni valle, ni orón o troje y mucho menos es derivación de Ophir. No es palabra quechua ni caribe, sino indo-hispana o mestiza. No tiene explicación en lengua castellana, ni tampoco en la antillana, ni en la lengua general de los Incas....sino corrupción del nombre del cacique de una tribu panameña, vecina del golfo de San Miguel, llamado Birú, al que los soldados y aventureros de Panamá dieron en llamar Perú. DE LA PUENTE CANDAMO JOSÉ AGUSTÍN, Reflexiones sobre la identidad nacional, Ob. Cit. Pp. 30-31, cit. PORRAS BARRENECHEA RAUL, El nombre del Perú, en Mar del Sur, n. 18, Lima, julio-agosto 1950, p. 37- 39 
vecinos de las ciudades que fundó, Pizarro les dio indios de encomienda. Vinculose así la posesión de indios con la condición de vecino de una ciudad, convirtiéndose la palabra vecino en sinónimo de encomendero...// ${ }^{64}$

Con la ocupación del Imperio Inca por parte de los hispanos, se realizó luego entre los conquistadores una división territorial. La Nueva Castilla, bajo el mando de Francisco Pizarro, y al sur la Nueva Toledo, bajo el gobierno de Diego de Almagro.

La disputa por la ciudad de Cuzco, que ambos consideraban bajo su jurisdicción, desencadenó el inicio de una guerra civil entre los conquistadores, que tuvo como trágicas consecuencias: la muerte de Diego de Almagro el 8 de Julio de 1538 efectuado por los partidarios de Pizarro; y luego, la muerte de Francisco Pizarro el 26 de Junio de 1541, realizada por los continuadores de Almagro.

El periodo sucesivo es el Virreinato, que empezó a partir de 1542. Inicialmente llamado Virreinato de la Nueva Castilla, y luego Virreinato del Perú.

Finalizada la penetración española en el Tahuantinsuyo, hubo una modificación en la política española. La corona hispana que inicialmente había otorgado amplias facultades a los conquistadores, comenzó a desarrollar mayor injerencia, promoviendo de esta manera la creación del Virreinato ${ }^{65}$.

${ }^{64}$ DE RÁVAGO BUSTAMANTE ENRIQUE, Ob. Cit., pp. 239

${ }^{65}$ Dentro de la Organización Jerárquica que se practicó en el Virreinato es conveniente señalar: como Autoridades Máximas: El Rey, quien era la autoridad absoluta, con facultades legislativas, ejecutivas y judiciales. Su poder en España estaba limitado por los fueros de las Cortes y la Justicia Mayor. El Consejo Real y Supremo de las Indias, creado en 1524. Sus principales funciones fueron la de asesorar al monarca en cuestiones del Nuevo Mundo y constituir la más alta autoridad consultiva, legislativa y jurisdiccional, después del Rey. Funcionó por más de dos siglos, siendo reemplazado en el siglo XVIII por la Secretaría de asuntos ultramarinos. EI Virrey era el representante directo del Rey y ejecutor del Consejo de Indias en el territorio de las Colonias hispanas. Tenían amplios poderes: presidían la Real Audiencia y era Capitán General de las fuerzas de tierra y de mar, así como responsable de la Administración Pública. Su designación inicial era por cuatro años y luego cambio a seis años. Estaba prohibido de adquirir propiedades e intervenir en la administración de justicia. Al finalizar su gestión era sometidos al juicio de residencia, que consistía en el derecho de cualquier autoridad subalterna o para cualquier súbdito del Reino, de denunciar abusos, delitos o injusticias cometidas por el virrey, quien debía permanecer en la Colonia mientras duraba la instructiva. Las Audiencias Pretoriales y Subordinadas, en las que destaca la Real Audiencia de Lima creada en 1544 , en ella se atendían los problemas civiles y penales en primera instancia y en apelación. La Casa de Contratación de las Indias, creada en 1503, fue un organismo desconcentrado de la administración metropolitana; estuvo ubicada en Sevilla. Inicialmente funcionaba como un establecimiento mercantil reuniendo en sus almacenes las mercaderías que se exportaban a las Indias, o que se importaban a España. Luego, le fueron asignando competencias científicas y jurisdiccionales. Los Cabildos Municipales, el gobierno de las ciudades fundadas por los conquistadores se encargó a una institución española llamada el Cabildo o Ayuntamiento, presidido por el Alcalde. El cabildo de Lima fue establecido el 22 de Enero de 1535 por el gobernador Francisco Pizarro. En 1783 se instituyen las Intendencias, bajo el mando del intendente, quien ejercía la directa representación virreinal, debía hacer frente a cada provincia, siendo el encargado de cumplir las leyes, gobernar los pueblos de su provincia, resolver los asuntos de policía y hacienda, vigilar e inspeccionar la administración de justicia y tener a su cargo la administración del Ejército. La creación de los Intendentes tuvo la importancia de hacer funcionar la administración sobre la base de Provincias en vez de las Audiencias y regularizar la división territorial, determinando las provincias y partidos que correspondían a cada circunscripción.
El Virreinato viene a convertirse en una estructura organizativa, tanto política como jurídica, unida a España. En su máxima expresión, el Virreinato del Perú, incluyó los actuales territorios de Colombia, Ecuador, Bolivia, así como los de Chile y Argentina. ${ }^{66}$

Naturalmente con la Conquista y más aun con el Virreinato, llegó al Perú el sistema jurídico imperante en España y Europa del siglo $\mathrm{XVI}{ }^{67}$.

De modo especial vemos como la reflexión sobre el nativo peruano, fue desarrollándose en distintos campos, no sólo desde un presupuesto teórico- antropológico, sino también con un reflejo concreto en el derecho, adquiriendo así una configuración jurídica. Corresponde a este tiempo el paso de la comunidad medieval fundada en la unidad cultural inspirada en el cristianismo, a una comunidad universal, basada sobre el respeto de la dignidad de la condición humana y sobre la igualdad de todos los hombres.

Este nuevo sistema implantado en el Perú, irá desarrollándose y enriqueciéndose durante tres siglos, con la atención de nuevas situaciones jurídicas, las que derivaron en una abundancia producción de textos jurídicos, que trataron de responder a éstas entre aciertos y desaciertos.

El derecho que regulaba estas nuevas situaciones, en el período colonial, es conocido como derecho indiano. Sobre el

${ }^{66}$ Es importante destacar que el Perú conquistado no era considerado como colonia, sino como una prolongación o provincia sujeta a los dominios de la corona de Castilla. Según explicaba Solórzano Pereira en la primera mitad del siglo XVII: -Ambas repúblicas de Españoles y de indios, ya hoy mezcladas, constituyen un cuerpo, y unos y otros reinos, aunque tan distantes $y$ apartados por mar y tierra, y de climas y constelaciones tan diferentes, se animan con una alma, y esperan de ella sola sus influencias y conveniencias/I (Política Indiana, Libro III, Capítulo XXXII). A fines del siglo XVIII, repetían solemnemente los Reyes que -España e Indias componían un solo cuerpo de monarquía, sin predilección particularll (Real Decreto del 8 de Julio de 1787). Es más, los matrimonios entre ambas razas fueron desde el principio, no ya permitidos sino estimulados, como lo comprueban los célebres enlaces de las princesas incaicas...// De Rávago Bustamante Enrique, Op. Cit. Pp. 256. Añade De la Puente citando a Basadre: -..la época del Virreinato fue una época dinámica y acesante, una época de creación. Dentro de la historia genética del Perú, el Virreinato señala el periodo del surgimiento y desarrollo de una nueva sociedad hispano-indígena-mestizacriolla y del surgimiento y desarrollo de una conciencia autonomista dentro de ella, paralelamente a análogos fenómenos en el resto de América hispana. La enumeración de los diversos gobernantes del Perú en esa época y de sus obras, o la lista de la leyes entonces vigentes sería, más que historia del Perú propiamente dicha, historia de España en el Perú, o historia del Estado español en el Virreinato peruano.... La historia del Perú empieza cuando los españoles se peruanizan en el contacto con el suelo, el ambiente, la vida o la gente que aquí encuentran; así como deja de ser mito, arqueología o leyenda cuando los indios se españolizan en una forma u otra, siquiera sea a través del idioma que sirve para ponerlos en contacto con el resto del mundo...// DE LA PUENTE CANDAMO JOSÉ AGUSTíN, Ob. Cit. Pp. 39- 40, cit. BASADRE JORGE, Notas sobre la experiencia histórica peruana, en Mercurio Peruano, Lima 1952, vol. 33, n. 299, Pp.78.

67 Señala el profesor Gallo: -... I conquistadores spagnoles..., oltre ad iniziare il sistematico sfruttamento dei nuovi territori, vi trasportarono altesi le loro istituzioni e la loro tradizione giuridica. II diritto latino-americano deriva quindi in larga misura da quello spagnolo e portoghese. La colonizzazione europea non ha però completamente distrutto le precedenti tradizioni delle popolazioni autoctone (Aztechi, Maya, Inca, ecc.)...// GALLO PAOLO, Introduzione al Diritto Comparato. Grandi Sistemi Giuridici. Volume Primo, Ob. Cit. Pp. 232 
concepto de derecho indiano, nos dice el profesor SánchezArcilla: - -...Se conoce el nombre de -derecho indianoll al conjunto de disposiciones que se aplicaron en las Indias, incluidas Asia y Oceanía. Dentro de él quedaron comprendidas: las normas creadas en la Península destinadas especificamente para las Indias (-derecho indianoll propiamente dichos); las normas creadas por las autoridades castellanas destinadas en las Indias (-derecho indiano criollo); el derecho castellano que, a falta de disposiciones especificamente indianas, se aplica como derecho subsidiario en las Indias; la costumbre, ya fuera metropolitana, criolla o indígena; la jurisprudencia de los tribunales metropolitanos y criollos; y la doctrina de los juristas, metropolitanos y criollos....68

Se trataba pues de un sistema jurídico que integraba los principios, leyes y costumbres aplicadas en las Indias, que fueron promulgadas y reconocidas por los monarcas españoles o sus autoridades delegadas, tanto en España como en América. Este derecho comprendía las normas creadas especialmente para las indias, el derecho castellano, utilizado a falta de disposiciones especiales en modo supletorio, y el derecho indígena, propio de los nativos. ${ }^{69}$

Luego el derecho indiano ira evolucionando, de ser una prolongación del derecho de Castilla, paso a convertirse en una normatividad especial adecuada para las situaciones

${ }^{68}$ SÁNCHEZ- ARCILLA BERNAL JOSÉ, Historia del derecho español, Ob. Cit. Pp. 290

${ }^{69}$ Una institución que tuvo mucha importancia en el campo del derecho peruano fue la Inquisición. Aunque no precisamente en relación con el derecho indiano, pues por disposición del Rey Felipe II los nativos peruanos estuvieron exceptuados del fuero inquisitorial, la acción del Tribunal sólo comprendía a las minorías blanca, mestiza o negra. El Tribunal de la Santa Inquisición de Lima fue creado en Lima en 1569. La corona la empleó como un organismo de control social, dirigiendo sus esfuerzos tanto a la defensa de la fe y la moral pública y privada, así como a la de la fidelidad a los monarcas y la paz social. -....En el contexto cultural en que surge la Inquisición española se sigue viendo al hereje -criptojudio en este caso-como un elemento de perturbación social; contra él, en diversas ocasiones $e$ injustamente, se desencadena la ira popular..... Es un dato significativo del doble principio que rige en los precedentes inmediatos al descubrimiento del Nuevo Mundo: a) el olvido de la esencial diferenciación del poder espiritual del poder secular -y, por ello, el peligro de la herejía y las implicaciones desestabilizadoras que implicaba-impulsaron el recurso al brazo secular rara extirparla y b) se desdibuja que el único camino para conducir a los espíritus a la fe es la predicación que respeta la libertad de las conciencias en su búsqueda de la verdad... Este doble planteamiento hizo que se aceptasen los criterios seculares de penalización para el hereje..../I LUQUE ALCALDE ELISA, La Inquisición. BORGES PEDRO (Dir.), Historia de la Iglesia en Hispanoamérica y Filipinas (Siglos XV-XIX) Volumen I: Aspectos Generales. Biblioteca de Autores Cristianos. Madrid 1992. Pp. 300-301. Los procesos se caracterizaban por una gran corrección formal y una red de garantías inimaginable para esa época, era falso el mito de que los acusados por los tribunales de la Inquisición terminaban casi siempre en la hoguera. En sus dos siglos y medio de existencia en el Perú (1569-1820), el Tribunal procesó 1477 personas en 1526 juicios. El número de juicios es mayor porque varias personas fueron procesadas en más de una oportunidad. El Tribunal de Lima sentenció a muerte a 32 personas, la mitad de ellos quemados vivos y otros tantos condenados al garrote. Fue abolido por decreto de las Cortes de Cádiz el 22 de febrero de 1813. El Virrey Abascal ordenó la publicación en Lima, el 30 de julio de ese año, del decreto de abolición. En 1814, cuando el rey Fernando VII fue restablecido en el trono, se dispuso que volviese a funcionar el Santo Oficio, pero su existencia fue ya más nominal que real. En el Perú fue abolido definitivamente a raíz del proceso emancipador con el cual se suprimió todo tipo de dependencia política de España. Una bibliografía importante sobre la inquisición en el Perú la encontramos en: CONGRESO DE indígenas. Claramente se advirtió que los problemas del territorio descubierto eran diferentes al de los hispanos y, en consecuencia, resultaba difícil que la legislación castellana regulara los conflictos que se planteaban en la realidad indiana ${ }^{70}$.

Establecer los períodos del derecho indiano es difícil a causa de su carácter casuístico y especial, así como de toda la complejidad de circunstancias que presidieron la labor colonizadora de España en América.

No obstante conviene destacar los siguientes períodos del derecho indiano:

Un período inicial del derecho indiano fundado en documentos como la Capitulación de Santa Fe, las Bulas Pontificias de Alejandro VI y posteriormente en las Leyes de Burgos (1512) ${ }^{71}$. Estos documentos, previos a la conquista del Perú, representaron la base del derecho indiano.

Luego en un período de consolidación del derecho indiano, destacan: la Capitulación de Toledo (1529), para algunos autores, esta capitulación representa el primer documento de carácter jurídico peruano.

Algunos historiadores coinciden en señalar que en sus primeras décadas, el derecho de Castilla era más que el derecho indiano, la ley que aplicaban los propios conquistadores $^{72}$.

LA REPUBLICA DEL PERU, Museo de la Inquisición y del Congreso. http://www.congreso.gob.pe/museo.htm (fecha de revisión: 25/05/2012)

70 Tanto el derecho propiamente indiano, es decir, el emanado de la metrópoli, como el derecho indiano criollo surgieron como una adaptación del derecho castellano a la realidad indiana. En este sentido, las leyes de Castilla constituían una especie de derecho general o ius commune frente al derecho indiano, que sería el ius proprium de las Indias. ... Por esta razón, la aplicación del derecho indiano prevalecía siempre sobre el castellano aun en los casos de contradicción entre la norma indiana y la castellana....En la medida que los tratadistas entendieron que el derecho romano justinianeo era derecho supletorio del castellano, también aquél se introdujo en el sistema de fuentes indiano. Si el derecho de Castilla era considerado como un ius commune frente al indiano, el verdadero ius commune, es decir, el derecho romano canónico, sería entonces respecto al indianoparafraseando a Baldo- un ius communissium...// SÁNCHEZ- ARCILLA BERNAL JOSÉ, Ob. Cit. Pp. 291

71 Las leyes de Burgos representaron la primera plasmación de una Declaración de los derechos a favor de los indios americanos, con la característica especial de haber sido promulgadas por el opresor en beneficio del oprimido, su promulgación fue precedida de fuertes reclamos sobre la justicia y bienestar a favor de los indios, siendo la Junta de Burgos la primera ocasión de reflexión en torno a la consideración sobre los indios americanos promovido por la Corona hispana.

${ }^{72}$ Algunos autores sostienen que a pesar de declaraciones a favor de los indios, sólo se les reconoció en la legislación una personalidad jurídica restringida. Se les consideró como sujetos de obligaciones y sus derechos fueron desconocidos o fuertemente limitados. Se les percibió como personas con capacidades disminuidas y, en consecuencia, necesitando de la tutela de parte de un tercero plenamente capaz. El profesor peruano Gonzales realiza un interesante trabajo sobre la condición de miserabilidad del indio peruano, señala lo siguiente: -...en la tradición del ius commune, la miserabilidad se aplica en razón de condiciones objetivas, mayormente económicas, caso por caso. En este nuevo desarrollo, en cambio, la determinación judicial para establecer la situación de miserabilidad deviene innecesaria, pues la miserabilidad se presume y aplica para todos los indios por el hecho de serlo. El caso de la situación de -privilegioll otorgada a los indios, se presenta como un Derecho que opera en cualquiera de las fuentes reconocidas por el ius commune; a nivel contractual, familiar o procesal. De tal modo que la miserabilidad, jurídicamente, presenta una propia ratio positiva que vale, por razones étnicas, para las relaciones jurídicas de un 
La convivencia del derecho indiano con las costumbres andinas y criollas produjeron un fenómeno de - síntesis que tuvo como consecuencia: por un lado de adaptar las normas existentes a casuísticas no previstas por ellas. El reconocimiento de la costumbre como fuente de derecho, no sólo indígena sino también criolla, desarrolló un papel muy importante en la vida jurídica del Nuevo Mundo.

En 1542 las Nuevas Leyes, promulgada por el rey Carlos I (emperador Carlos V), fueron una declaración en defensa de los derechos de los indios. Recogía el pensamiento de la Escuela de Salamanca fundada en el principio inviolable de la libertad del hombre. ${ }^{73}$ En ésta se establecieron la existencia de dos virreinatos, el de Nueva España y el de Nueva Castilla o del Perú. El punto central de las Nuevas Leyes giraba en torno a la eliminación del otorgamiento de nuevas "encomiendas" y la prórroga de las ya existentes, castigando con penas severas a quien injuriara, hiriera o matara a un indio $^{74}$.

En este período no faltaron choques entre misioneros y conquistadores. Esta tensión es bien expresada por el profesor Aldea Vaquero, al señalar: _...La Corona y la Iglesia, $y$ en su nombre los Virreyes, los obispos y las Audiencias encarnaban casi siempre- y a pesar de todas las flaquezas humanas- lo mejor del alma de España, el papel del ángel. Pero también - y hay que reconocerlo sin tapujos- muchos encomenderos, muchos corregidores, muchos caciques, muchos explotadores de minas, muchos comerciantes, tal cual extraño Gobernador, - todos ellos codiciosos de riquezas,representaron el tristísimo papel de la bestia. Con las dos fuerzas en conflicto, ya lo sabemos, se ha hecho siempre la historia. Y también la nuestra... ${ }^{75}$

Durante este tiempo se legisló tanto desde España, especialmente por medio del Consejo de Indias, como por el derecho creado y aplicado por las autoridades hispanas residentes en Perú, conocido como Derecho indiano criollo. En el año 1551 se creó en Lima la Universidad Nacional Mayor de San Marcos, siendo la primera Universidad creada en

conjunto de comunidades de personas, presentándose de este modo como una especie de -derecho singular|| o particular...// GONZALES MANTILLA GORKI, Ob. Cit., pp. 298

${ }^{73}$ El año 1542 marca un verdadero hito en la crisis moral de la colonización española de América. La Corona se encontró abrumada por las denuncias de abusos que le llegaba especialmente sobre las conquistas en el Perú y en el Nuevo Reino de Granada y decidió convocar en Valladolid una Junta de teólogos y juristas que discutiera el tema y perfilara una solución para el mismo. El resultado de esta pragmática política lo conocemos bien, y fueron las Leyes Nuevas del 20 de noviembre de 1542....// LUCENA MANUEL, Crisis de la conciencia nacional: las dudas de Carlos V. PEREÑA LUCIANO (dir.) Francisco De Vitoria y la Escuela de Salamanca. La ética en la conquista de América. Consejo Superior de Investigaciones Científicas. Volumen XXV. Madrid. 1984. pp. 196.

${ }^{74}$ Las Leyes Nuevas y su rigurosa aplicación provocaron una serie de violentas oposiciones, pues los poseedores de encomiendas se consideraron perjudicados. En el Perú llevará al enfrentamiento entre la autoridad virreinal y los encomenderos, en modo especial entre el primer virrey del Perú Blasco Núñez Vela y Gonzalo Pizarro, hermano del conquistador Francisco Pizarro y representante de los encomenderos. Las pugnas hispanas terminará con la muerte del propio virrey el 18 de enero de 1546. Luego llegó al virreinato Pedro de La Gasca con el título de presidente de la audiencia de Lima. Su función fue la de juzgar los acontecimientos y dar los nombramientos y las instrucciones necesarias para la aplicación de las Leyes Nuevas, con las modificaciones que considerase oportuno introducir.
América. Aprobada por el emperador Carlos $\mathrm{V}$ por privilegio Real y posteriormente por la Bula Pontificia confirmatoria, la Universidad de los Reyes de Lima, como inicialmente era conocida, tenía como sede el Monasterio de Santo Domingo. La Universidad de San Marcos alcanzó rápidamente una dimensión continental, pues de ella egresaban profesionales que pasaron a formar parte de la alta burocracia americana, tanto secular como religiosa. Especialmente en el Derecho, se dio el paso de los juristas graduados en Salamanca a los juristas graduados en Lima, cuya sensibilidad y entendimiento del mundo indígena eran más realistas, pues pertenecían, generalmente por rama materna, a la raza mestiza que iba poblando el Nuevo Mundo ${ }^{76}$.

La abundante normatividad jurídica que regulaba la diversidad de situaciones presentadas en las Indias, planteó el problema del conocimiento de las leyes, tanto en el Perú como en el mismo Consejo de Indias. Se mostró una apremiante necesidad: la de recopilar las leyes.

En ese sentido, destacables fueron los trabajos de recopilación iniciados por Juan de Ovando entre 1569 y 1571. En Perú la labor del jurista peruano Gaspar Escalona y Agüero con su obra el Código Peruano en 1635, que - ... no es, pues, frente a las recopilaciones generales, una de tipo territorial, sino de carácter personal, si bien referida únicamente a los indios de las provincias del Perú...el propósito de Escalona es reunir todas las normas referentes a los indios en forma sumaria, concisa, - en libro manual// breve volumen para uso de los aborígenes y de las autoridades indianas... ${ }^{77}$.

En 1680, al Rey Carlos II promulgó la Nueva Recopilación de las leyes de Indias. Dividida en nueve libros, subdividida en 218 títulos y en millares de leyes. Tuvo un carácter general, por lo que fue vigente también en las Indias. La obra contó con el aporte de los notables juristas Antonio de León Pinelo y Juan de Solórzano y Pereira.

Por último, se puede considerar un período de reformismo, ya en la etapa Borbónica, en la que destaco el continuo crecimiento de la legislación indiana ${ }^{78}$

${ }^{75}$ ALDEA VAQUERO QUINTÍN, El indio peruano y la defensa de sus derechos (1596- 1630) Consejo Superior de Investigaciones Científicas (Madrid). Fondo Editorial de la Pontificia Universidad Católica del Perú. Madrid- Lima 1993. Pp. 38. Fueron muchos los religiosos que ejemplificaron con coherencia la vida cristiana, memorable es el testimonio del Padre Jesuita José de Acosta. Al respecto, señala Nieto: - ...La ventaja de un hombre como José de Acosta fue que vivió de cerca la realidad americana y no se redujo a desarrollar sus consideraciones a partir de lo que decían o escribian las informaciones y testigos de nuestras tierras...Durante su permanencia en el Perú el trabajo apostólico entre los indios recibió particular impulso.../I NIETO ARMANDO, El padre Jose De Acosta. Ediciones Vida y Espiritualidad. Lima 1989. pp. 5- 7

${ }^{76}$ La característica de este grupo social, conformado tanto por miembros de la nobleza española, como por la nueva categoría social que eran los mestizos, por lo general hijos de nobles y de mujeres nativas, que estudiaron en la Universidad de San Marcos, permitían la discusión y la negociación, previa a la aplicación de una sentencia o a resolver un diferendo.

77 MANZANO MANZANO JUAN, Historia de las recopilaciones de indias II. Siglo XVI. Tercera edición. Ediciones de Cultura hispánica. Madrid 1991.Pp. 188- 189

${ }^{78}$ Con la llegada de los Borbones se produce un cambio radical en la administración y vinculación de la Península.... El estatus jurídico de los reinos de Indias se equipara con el de reinos europeos pertenecientes a la monarquía española, y desde el punto de vista del Derecho Público no se los consideraba un país extranjero, existiendo una perfecta igualdad, unidad y 
Se introdujo la figura de la Intendencia como nuevo modelo jurídico administrativo a regir en el Virreinato. Durante este período España acoge la influencia del pensamiento liberal que junto con un explícito catolicismo fueron plasmados en la Constitución de Cádiz en 1812.

Es evidente pues, en todo este tiempo de colonia española, el nacimiento y consolidación de un sistema jurídico orientado a salvaguardar la integridad del indio, sobre la base de los derechos personales del individuo. Sistema jurídico que tuvo una clara consideración sobre los indígenas como seres humanos, que aceptando las contradicciones entre la teoría, la norma jurídica y la práctica, reconoció la diversidad cultural en el Perú.

De esto se explica el reconocimiento de la costumbre indígena como una fuente de derecho ${ }^{79}$.

Esta distinción es fundamental, pues si por una cuestión específica, la persona esta impedida de actuar (en este caso los indios americanos), no por esto son menos personas. La titularidad de los derechos viene extendida igualmente a aquellos que tienen la potencialidad de ser autoconscientes y libres, pues prevale la condición intrínseca de la dignidad de toda persona humana.

Se trata del reconocimiento que la diversidad no sólo no excluye la titularidad de los derechos, sino ella misma da lugar a un derecho fundamental a la asistencia, creando así una obligación de parte de quien puede ofrecerla.

\section{Conclusiones}

Los hechos históricos de alcance universal como el descubrimiento de América evidenció en el viejo continente una unidad cultural vivida en aquel tiempo, una reductio ad unum de carácter religioso y filosófico, con incidencia a nivel político y jurídico. El derecho común que nació en Bolonia tuvo una expansión en diversas universidades hispanas, el mismo que sirvió de inspiración para la formación del derecho indiano.

La Conquista del Perú evidenció una perspectiva histórica sintética, centrada en la formación de la cultura mestiza, la cual le brinda una nueva identidad, que no es sólo hispana ni solamente incaica.

Esta síntesis cultural marcó en sus inicios una primera interrogante: ¿si el indio peruano era considerada o no persona humana? La respuesta a este cuestionamiento llevó a una profunda reflexión de parte de teólogos y juristas españoles del siglo XVI, entre los cuales sobresalió Francisco De Vitoria y la Escuela de Salamanca. De Vitoria en sus justos títulos realizó una reflexión filosófica-jurídica en la que reconoció que los indios peruanos eran personas humanas, y por tanto sujetos de derechos.

El desarrollo de esta concepción permitió a su vez reconocer que la persona humana por su propia naturaleza es un ser social y tiene un derecho natural a la comunicación, por tanto se justifica un derecho a la comunicación entre los pueblos. Además delineo la expresión moderna del principio internacional de la -autodeterminación de los pueblos. reciprocidad en el gobierno y atención de los negocios de unos y otros dominios y de sus respectivos habitantes. Al acceder al trono español los monarcas borbones, el cambio de orientación en la política de esta dinastía no se reflejó en la condición jurídica que la Península asignó a los territorios americanos, ya que la legislación de Indias del siglo XVIII no lo calificó como colonias o factorías. Excepcionalmente se les dio el nombre de dominios, pero sin que este calificativo pudiera entenderse como una disminución en el estatus jurídico de las regiones de ultramar... SAN MARTINO DE DORMí LAURA, Iberoamérica. Editorial de Ciencia y Cultura. Buenos Aires. Servicio de Publicaciones- Facultad de Derecho Universidad Complutense. Madrid 2002. pp. $45-46$

${ }^{79}$ En el Perú mestizo se puede advertir la presencia de muchas formas de ser peruano, pero no de varios países.... El cabal conocimiento de nuestra historia, de las fuentes comunes, no sólo subraya la verdad de nuestro origen, sino la comunidad entre los peruanos.... DE LA PUENTE CANDAMO JOSÉ AGUSTín, Ob. cit. Pp. 45 